\title{
Intracellular Urokinase uPA-PAI-1 Complex: Disruption by Small Molecule Targets Hypoxically Programmed Glioma Cells
}

\author{
Nagarekha Pasupuleti' ${ }^{1}$, Anthony Valenzuela1, Yamini Manohar ${ }^{1}$, Sundeep Dugar ${ }^{2}$, Jann Sarkaria ${ }^{3}$ and Fredric \\ Gorin $^{1 *}$
}

${ }^{1}$ Departments of Neurology (School of Medicine) and Molecular Biosciences (School of Veterinary Medicine), University of California Davis, USA

${ }^{2}$ Sphaera Pharma Inc., Singapore and Sphaera Pharma Pvt. Ltd., India

${ }^{3}$ Department of Radiation Oncology, Mayo Clinic, USA

Submission: January 13, 2018; Published: March 23, 2018

*Corresponding author: Fredric Gorin, Professor and Chair, Departments of Neurology (School of Medicine) and Molecular Biosciences, University of California Davis, USA, Tel: 916-734-6284

\begin{abstract}
High grade gliomas (HGGs) are primary lethal CNS cancers. Elevated protein levels of uPA-PAI-1 complexes are a highly predictive biomarker for a number of highly proliferative solid cancers predisposed to infiltrate and metastasize. We report a new small molecule (Cmpd10357) that rapidly disrupts intracellular uPA-PAI-1 complexes and which temporally corresponds with the relocation of endosomes containing urokinase protein cargo. 'Mis-trafficking' of these uPAS endosomes by Cmpd10357 and its parent compound UCD38B triggers AIF-mediated, caspase-independent glioma necrosis. We now identify that Compound10357 and UCD38B disrupt intracellular uPA-PAI-1 complexes to trigger this programmed cancer cell necrosis. This novel drug target suggests a potential functionality for elevated levels of uPA-PAI-1that has been identified in many high grade solid cancers. Hypoxia and acidosis inhibit cell cycle progression of surviving populations and promote hypoxically reprogrammed glioma cells capable of initiating tumor regrowth. High grade gliomas have elevated basal levels of urokinase (uPA) that were found to increase with hypoxia. Persistent hypoxia for five days markedly increased expression of the urokinase endogenous inhibitor PAI-1, and of the hypoxic transcription factors HIF $1 \alpha$ and HIF $2 \alpha$. Expression of the embryonic transcription factors Oct 4 and Nanog is also transcriptionally regulated by HIF $2 \alpha$ and a subpopulation of hypoxic glioma cells were identified as co-expressing PAI-1, Nanog and Oct4. Normoxic patientderived xenografted (PDX) glioma lines also express PAI-1 and contain subpopulations as as co-expressing PAI-1, Nanog and Oct4. Cmpd10357 comparably kills high grade human glioma cell lines and PDX glioblastoma lines, including temozolomide-resistant PDX glioma cells independent of caspase activation. These data suggest that Cmpd10357 or related congeners could be employed, in conjunction with conventional and antiangiogenic therapies, to kill quiescent glioma cells residing in hypovascularized or perinecrotictumor microenvironments.
\end{abstract}

Keywords: Hypoxic gliomas; Glioma initiating cells; Glioma 'stem-like' cells; Urokinase plasminogen activator (uPA); Plasminogen activator inhibitor type 1 (PAI-1); Intracellular uPA-PAI protein complex; Intracellular uPA-PAI drug target; Embryonic stem cell transcription factors; Patient-derived xenografted (PDX) gliomas

Abbreviations: HGGs: High-Grade Gliomas; GICs: Glioma Initiating Cells; GSC's: Glioma 'Stem-Like' Cells; PDX: Patient Derived Xenograft; HIFs: Hypoxia inducible factors; uPAS: Urokinase Plasminogen Activator System; uPA: Urokinase-Type Plasminogen Activator; uPAR: The uPA Receptor; PAI-1 and PAI-2: Plasminogen Activator Inhibitors; tPA: Tissue-Type Plasminogen Activator; TMZ: Temozolomide

\section{Background and Importance}

High-grade gliomas (HGGs) are an aggressive group of primary glial brain cancers characterized by rapid, infiltrative growth. The most aggressive of these HGGs, WHO grade 4 astrocytomas, contain spontaneously hypoxic, necrotic, and hemorrhagic tumor domains resulting from rapid proliferation with ineffective neo vascularization. These hypovascularized, tumor regions harbor populations of glioma cells capable of selfrenewal, and tumor regrowth [1] and are resistant to radiation therapy, anti-mitotic agents, and anti-angiogenic therapies $[2,3]$. These hypoxic cancer cells have been shown to be non- proliferative or minimally proliferative enabling them to survive anti-mitotic drugs, radiation therapy, and anti-angiogenic agents [4]. Conventional therapies and anti-angiogenic therapy has been demonstrated to enrich for 'stem-like' and additional cancer initiating cells, which have been reprogrammed by hypoxicinduced transcription factors, notably HIF $2 \alpha$ [5]. Consequently, hypoxic regenerative cancer cells are now recognized as a primary impediment to the successful treatment of highly proliferative cancers due to their roles in resistance, recurrence and metastasis $[6,7]$. 
Hypoxic-ischemic and perinecrotic tumor domains of HGGs demonstrate increased expression of several components of the urokinase plasminogen activator system (uPAS); uPA, PAI1, UPAR, reviewed in [8-10]. Hypoxic-ischemic glioma cells express high levels of uPA-PAI-1; a biomarker shown to be highly predictive of cancer recurrence and metastasis; notably in breast cancer and high grade glial cancers [11-13]. PAI-1 binds to uPA complexed with its receptor (UPAR) at the cell surface. In most instances the complex is endocytosed with the assistance of LRP1 [14]. The quaternary complex (UPAR-uPA-PAI-1-LRP-1) enters cells primarily by endocytosis and the complex is partitioned so the LRP-1 and UPAR receptors are recycled and UPA and PAI-1 are degraded [15].

PAI-1, when bound to uPA, inhibits the latter's enzymatic activity and cellular adhesiveness. When normal cell-cell contact is established, there is inhibition of PAI-1 expression and it is not expressed in normal brain or vascular cell types [8]. Paradoxically, persistently elevated levels of uPA-PAI-1, measured by ELISA, are well documented as a biomarker closely corresponding with cancer recurrence and dissemination [1113]. Despite its clinical importance as a cancer biomarker, the biological importance of uPA-PAI-1 is not understood.

Hypoxia is a key negative prognostic feature of solid cancers including HGGs, gastric, colon, pancreas, lung and breast [16] promoting a more aggressive cancer cell phenotype [17]. Hypoxia inducible factors (HIFs) are well characterized transcription factors that regulate gene expression under hypoxia [18]. HIF $1 \alpha$ is rapidly expressed in the setting of acute hypoxia and transcribes genes that inhibit cell migration, growth, energy metabolism, and apoptosis, while stimulating angiogenesis [19]. In contrast, HIF $2 \alpha$ expression is delayed and expressed under persistent hypoxic conditions facilitating the cell's adaptation to a hypoxic environment. HIF1 $\alpha$ regulates the Notch ligand Jagged 1 (JAG1) leading to increased uPA expression [20-22]. HIF2 $\alpha$ directly activates the PAI- 1 promoter and increases expression [23-25]. HIF $2 \alpha$ also transcriptionally activates early embryonic stem cell transcription factors, including Oct4, Nanog, Sox2, and regulatory pathways including Notch, and c-myc [26-28].

The uPAS system is an attractive novel target for anticancer therapy and inhibitors of uPA bound to plasmalemma luPAR has resulted in anti-cancer cytostatic agents. In contrast, here we describe cytotoxic small molecules that bind to the active site of UPA, disrupt the intracellular uPA-PAI-1 protein complex. Previously, we described that a patented cell permeant derivative of amiloride, 5-benzylglycinyl amiloride (UCD38B) [29], triggered relocation of uPAS endosomes. Mis-trafficking of these uPAS endosomes led within hours to irreversible caspase-independent, necrotic cell death in gliomas mediated by apoptotic inducible factor (AIF) [30]. The anti-cancer cytotoxicity caused by UCD38B in glioma and breast cancer cell types was shown to be independent of cell cycle or autophagy $[29,31]$. However, UCD38B is not very potent, and despite being a competitive enzymatic inhibitor of uPA its intracellular drug target remained unclear. Here, we describe the anti-cancer cytotoxicity of a new small molecule, Cmpd10357 that kills glioma cells by the analogous programmed necrotic cell death mechanism as UCD38B, but is at least 20 -fold more potent.

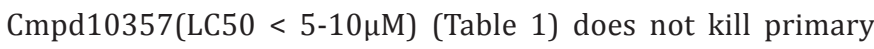
astrocytic cultures, but is cytotoxic to human and canine high grade glioma cell lines and to primary high grade glioma cultures from patient derived xenografts (PDX), including those resistant to temozolomide (TMZ). We and others reported elevated expression of UPA in high grade gliomas [32] and that UCD38B and its cell impermeant, cytostatic homolog, UCD74A, bind to the active site of uPA $[29,30]$. Using the more potent cell permeant Cmpd10357, we now identify that intracellular uPA and PAI- 1 complex is the putative drug target of Cmpd10357 and UCD38B. Three normoxicPDX glioma cultures demonstrate coexpression of PAI-1 and embryonic stem cell markers Oct4 and Nanog. Expression of these embryonic transcription factors and increased expression of PAI-1 was observed following 5 days of persistent hypoxia in clonal LN229 glioma cells. Cmpd10357 targets and engages PAI-1 triggering AIF-mediated cell death mechanism of action.

Table 1: Cell Permeant and Impermeant Small Molecule Inhibitors of Urokinase plasminogen Activator (uPA).

\begin{tabular}{|c|c|c|c|c|c|}
\hline Compound & Structure & $\begin{array}{l}\text { uPA IC50 } \\
\text { (uM) }\end{array}$ & Cell Permeable & $\begin{array}{l}\text { LC50 (uM) } \\
\text { U87 gliomas }\end{array}$ & uPAS endosomal relocation \\
\hline $\begin{array}{c}\text { UCD38B+ } \\
\text { [42] }\end{array}$ & & 3 & Yes & 100 & Yes \\
\hline $10357^{*}$ & & 11 & Yes & 6 & Yes \\
\hline $\begin{array}{c}\text { UCD74A } \\
\text { [42] }\end{array}$ & & 17 & No & $\begin{array}{c}\text { Not } \\
\text { cytotoxic }\end{array}$ & No \\
\hline
\end{tabular}




\section{Materials and Methods}

\section{Drugs and antibodies}

UCD38B (5-benzylglycinyl-3-amino-6-chloro-N-(diaminomethylene) pyrazine-2-carboxamide and UCD74A (5-glycinyl-3-amino-6-chloro$\mathrm{N}$-(diaminomethylene) pyrazine-2-carboxamide) were synthesized as described previously [33]. Drugs stocks of $250 \mathrm{mM}$ were constituted in DMSO stored at $-20{ }^{\circ} \mathrm{C}$ and reconstituted for each experiment to a final concentration of $250 \mu \mathrm{M}$. 3-amino-5-arylamino-6-chloro-N(diaminomethylene) pyrazine-2-carboximide (Cmpd10357) was reconstituted to a final concentration of $250 \mu \mathrm{M}$ in DMSO and stored at -20 ${ }^{\circ} \mathrm{C}[34]$.

Human anti-PAI-1 mouse monoclonal (IgG1specific), human anti-PAI-1 goat polyclonal, human anti-Nanog rabbit polyclonal, human anti-Oct4 rabbit polyclonal, (Abcam, Cambridge, MA), human anti-uPA mouse monoclonal and human anti-uPAR mouse monoclonal (1:100 dilution; American Diagnostica, Stamford, CT) were used as primary antibodies. Goat anti-mouse secondary antibody (1:20000, LicorBiosciences, Lincoln, NE) was used for protein visualization on immunoblots.

\section{Cell culture}

U87MG and LN229 human glioma cell lines were derived from high grade glial cancers and obtained from the American Type Culture Collection (Manassas, VA). Primary glioma cultures from patient-derived glioma xenografts (PDX), GBM10, GBM12, and GBM39 were obtained from Dr. Sarkaria's lab (Mayo Clinic) and were generated as described elsewhere $[35,36]$. Cells were grown at $37^{\circ} \mathrm{C}$ and $5 \% \mathrm{CO} 2$ in Dulbecco's modified Eagle's medium (Gibco). DMEM or MEM (for U138MG) was supplemented with $10 \%$ fetal bovine serum (Hyclone Laboratories, Rockford, IL), $1 \%$ L-glutamine (Gibco), 100U/ml penicillin and $100 \mathrm{mg} / \mathrm{ml}$ streptomycin (Gibco, Grand Island, NY). PDX glioma lines have been shown to be genetically heterogeneous within and between the different lines [51]. This was the rationale for using the genetically validated and homogeneous LN229 glioma cell line (ATCC® CRL-2611 [37] to study hypoxic regulation.

\section{Cell death assay}

Lactate dehydrogenase (LDH) assay measured the release of cytosolic LDH from dead and dying glioma cells as described previously [29,31]. Briefly, ten thousand cells per well were plated in 96-well microtiter plate and treated with the drugs for $24 \mathrm{~h}$ at $37^{\circ} \mathrm{C}, 5 \% \mathrm{CO} 2$. LDH assay was performed according to the manufacturer's protocol (Clontech Laboratories, Mountain View, CA). Absorbance was read at 492nm using a SpectraMax M3 with SoftmaxPro software (LifeSciSoft, Kingston, NY).

\section{SiRNA transfections}

On-Target plus siRNA and control siRNA for UPA and UPAR were purchased from Dharmacon RNAi Technologies (Lafayette, CO). Transfections were performed using Dharmacon siRNA transfection reagent according to manufacturer's instructions and protocol. Cells were harvested 3, 4, and 5 days posttransfections.

\section{shRNA transfections}

Human PAI-1 constructs containing 29 mer shRNA constructs and non-effective 29-mer scrambled shRNA cassette in retroviral vector was purchased from Origene Technologies Inc., (Rockville, MD).Following transient transfections in U87 glioma cell line, cells were maintained in growth medium containing $0.5 \mu \mathrm{g} / \mathrm{ml}$ puromucin for clonal section. Transfectionswere performed using transfection reagent provided bythe manufacturer and following their protocol.

\section{Protein fractionation and immunoblotting}

Protein extracts were made in RIPA (radio immuno precipitation assay) lysis buffer (Cell Signaling, Danvers, MA) and $50 \mu \mathrm{g}$ of protein was loaded on SDS-PAGE. Protein samples were size-fractionated by electrophoresis through $12 \%$ SDS-PAGE and transferred onto nitrocellulose membrane by immunoblotting. Blocking buffer (Licor Biosciences, Lincoln, NE) diluted 1:1 in $1 \mathrm{X}$ PBS was used for $1 \mathrm{~h}$ at room temperature to prevent non-specific binding sites. Primary antibody incubation was performed overnight at $4{ }^{\circ} \mathrm{C}$. The secondary antibody incubation was carried out at room temperature for $1 \mathrm{~h}$. Goat anti-mouse, goat anti-rabbit and donkey anti-goat secondary antibodies from Licor Biosciences were used at 1:10000 dilution [29]. Bands were visualized and quantified using Odyssey Infrared Imager (Licor Biosciences, Lincoln, NE).

\section{Quantification of uPA-PAI-1 protein content}

Whole cell extracts were isolated using RIPA lysis buffer that denatures plasmalemmal proteins. For cytosolic and membrane fractions, glioma cells were harvested and cell pellet was washed in ice cold PBS. After centrifugation at $300 \mathrm{Xg}$ for $10 \mathrm{~min}$ the pellet was resuspended in cytosolic protein extraction buffer (10mM PIPES, pH6.8, 5mM EDTA, 0.01\% digitonin) containing protease inhibitor cocktail. Following $10 \mathrm{~min}$ incubation at 4 ${ }^{\circ} \mathrm{C}$, the samples were centrifuged at $1000 \mathrm{Xg}$ for $10 \mathrm{~min}$. The supernatant was collected as cytosolic fraction. The pellet was then resuspended in membrane protein extraction buffer (10mM PIPES, pH 7.4, 5mM EDTA, 0.5\% Triton X-100) containing protease inhibitor cocktail. The samples were incubated for $30 \mathrm{~min}$ at $4{ }^{\circ} \mathrm{C}$ with gentle agitation followed by centrifugation at $6000 \mathrm{Xg}$ for $10 \mathrm{~min}$. The supernatant was collected as a membrane enriched intracellular fraction. All steps were performed at $4{ }^{\circ} \mathrm{C}$. The uPA-PAI-1 complexeswithin the cytosolic and membraneenriched fractions from human U87 glioma cells were quantified using a commercially available ELISA kit (Molecular Innovations, Inc. Novi, MI). The ELISA selectively measures UPA-PAI-1 protein complexes and not the individual protein constituents. Protein extracts $(100 \mu \mathrm{g})$ from glioma cells were incubated with or without UCD38B $(250 \mu \mathrm{M})$ or Cmpd10357 $(10 \mu \mathrm{M})$ for $1 \mathrm{~h}$ and $4 \mathrm{~h}$. Following treatments, the protein extracts were transferred into a 96-well plate coated with uPA antibody (provided by the manufacturer). PAI-1 antibody was used as a second antibody to quantify the PAI-uPA complex at an absorbance $450 \mathrm{~nm}$. Purified human PAI-uPA complex provided in the kit was used to generate 
a standard curve with a linear correlation coefficient of $\mathrm{R}=0.998$ Each experiment using UCD38B, Cmpd10357, or vehicle control, was performed in triplicate and repeated independently three times.

\section{Intracranial mouse xenografts}

Athymic nude mice (6 week old females) were acquired from The Jackson Laboratory (Sacramento,CA). Female mice were selected that permitted group housing and reduced the number of animals needed to demonstrate regional expression of PAI1 and Nanog within intracerebral glioma cells. Male and female mice will be used in future experiments evaluating possible drug efficacy. The immunodeficient mice were housed separately from other animals at the UC Davis Vivarium under HEPA filtered air, and provided with sterilized food, water and bedding. Mice were anesthetized in an induction chamber with $2-3 \%$ isoflurane delivered at one liter oxygen per minute until deep sedation was established. Unresponsive mice were transferred to a Stoelting stereotaxic frame (Stoelting Co., Wood Dale, IL) where they were maintained under deep anesthesia using a nose cone coupled to the isoflurane source. All surgical procedures were carried out using approved aseptic techniques (detailed in UC Davis Survival Surgery Guidelines for Rodents). PDX glioma cells were injected intracerebrally into athymic mice as described previously [36]. Briefly, the scalp was opened with a $1.0 \mathrm{~cm}$ incision and a single burr hole was drilled $2.5 \mathrm{~mm}$ lateral and $1.0 \mathrm{~mm}$ anterior to bregma in the left parietal bone, through which 50,000 GBM12 glioma cells in a $2.0 \mu \mathrm{l}$ infusion, were injected at a depth of 4.0 $\mathrm{mm}$ from the brain surface (corpus striatum).

\section{Drug administration and brain harvest}

Cmpd10357 was intraperitoneally injected at a concentration of $10 \mathrm{mg} / \mathrm{kg} /$ day $(80 \%$ PEG400/20\% $\quad$ PBS vehicle) for 8 consecutive days or 3 days. Drug treatment was started at 15 days post-implantation. Brains were harvested $24 \mathrm{~h}$ or $48 \mathrm{~h}$ after the final drug administration. A transcardial formalin perfusion was performed while animals were under deep anesthesia induced by an intraperitoneal injection of $0.22 \mu \mathrm{l} / \mathrm{g}$ euthasol (sodium pentobarbital and sodium phenytoin, Virbac Corp. Fort Worth, TX).

\section{Immunocytochemistry}

Human glioma cell lines (LN229, U87MG) or gliomas from patient derived xenografts (GBM10, GBM12, and GBM39) were grown on chamber slides. Cell cultures were treated with Cmpd10357 or DMSO vehicle $(0.01 \%)$ for 30,60 , and $120 \mathrm{~min}$ at $10 \mu \mathrm{M}$ at $37^{\circ} \mathrm{C}$. Glioma cells were washed with PBS, fixed with $4 \%$ paraformaldehyde in PBS at room temperature for $15 \mathrm{~min}$, followed by washing with PBS and permeabilized with $80 \%$ methanol in PBS at $-20{ }^{\circ} \mathrm{C}$ for $15 \mathrm{~min}$. Blocking of nonspecific antibody binding sites was performed using 3\% nonfat dry milk/1\% BSA in PBS for $1 \mathrm{~h}$ at room temperature. Cells were incubated with primary antibody in $0.1 \%$ BSA/PBS at 4 ${ }^{\circ} \mathrm{C}$, overnight at 1:100 dilutions. Secondary antibody against mouse or rabbit, conjugated with Alexa Fluor 488, 594 and 647
(Molecular Probes, Eugene, OR) was used at 1:500 dilution in $0.1 \%$ BSA/PBS and incubated for $1 \mathrm{~h}$ at room temperature. After the PBS wash, the slides were mounted with mounting media containing 4', 6-diamidino-2-phenylindole (DAPI; Molecular Probes, Eugene, OR). Images were captured using 40X objective with a spinning disk confocal microscope (Olympus IX81).

\section{Immunohistochemistry}

Formalin fixed, paraffin embedded tissue blocks were cut into $5 \mu \mathrm{m}$ sections with a rotary microtome (Microm Heidelberg HM 330), mounted on Superfrost Plus slides (Fisher Scientific, Pittsburgh, PA), and oven baked at $60^{\circ} \mathrm{C}$ for 15 mins after overnight air drying. Baked slides were cooled at room temperature before they were deparaffinized with xylene and rehydrated with serial dilutions (95\%, 70\% and 50\%) of histological grade reagent ethanol. They were briefly rinsed with distilled water before antigen retrieval. Antigen retrieval was performed by steaming in sodium citrate buffer $(10 \mathrm{mM}$ sodium citrate, $\mathrm{pH}$ 6.0, with $0.5 \%$ Tween 20 ) for 30 mins, followed by $2 \mathrm{~h}$ soak in the blocking buffer $(10 \%$ donkey serum in $0.05 \mathrm{M}$ TBS with $1 \%$ bovine serum albumin (Sigma) at room temperature. Slides were rinsed in Tris-buffered saline (TBS, $0.05 \mathrm{M}$ ) containing $0.025 \%$ Triton $\mathrm{X}-100$ and then stained for either PAI-1 or Nanog. Slides were then incubated with the primary antibody either mouse antiPAI-1 monoclonal, IgG1specific antibody or rabbit anti-Nanog polyclonal antibody (Abcam, Cambridge, MA) in a 1:100-1:200, in antibody diluent (1\% BSA in 0.05M TBS). Slides were rinsed and incubated in secondary antibodies conjugated with Alexa Fluor 488 or 594 (1:500 dilution, Molecular Probes) for 2 hour at room temperature. Sections were rinsed again (TBS with Triton X-100) followed by distilled water before mounting with VectaShield mounting media containing diamidino-2-phenylindole (Vector Laboratories, Burlingame, CA). Immunostaining was visualized using 40x objectives on a motorized inverted spinning disk confocal microscope (Olympus IX81, Olympus America Inc., Center Valley, PA).

\section{Statistical Analysis}

Data are presented as mean \pm standard deviation and statistical significance identified using one-way analysis of variance and Bonferroni's nonparametric, multiple pairwise comparisons using Sigma Stat software version 2.00 (SPSS Science Inc, Chicago, IL).

\section{Results}

\section{Cmpd10357 is selectively cytotoxic to human and canine high grade gliomas}

The concentration dependent cytotoxicity (LC50) of Cmpd 10357against normoxic human glioblastoma cell lines was measured using the lactate dehydrogenase assay [29] following $24 \mathrm{~h}$ drug treatment and summarized in Table 2. Cmpd10357 is cytotoxic against four human HGG cell lines, five patient-derived xenografted glioma lines (PDX) and two naturally occurring high-grade canine glioma and oligodendroglioma cell lines, but 


\section{Open Access Journal of Neurology \& Neurosurgery}

did not demonstrate cytotoxicity against primary astrocytic cultures (Table 2). Anti-glioma cytotoxicities of Cmpd10357 were comparable $(\mathrm{LC} 50<10 \mu \mathrm{M})$ (Supplementary Figure 1,2) against an array of human and canine HGG cells, including two GBM temozolomide-resistant PDX lines, GBM 6 TMZ and GBM 38 [38].

Table 2: Concentration of Cmpd 10357 (LC50) that kills $50 \%$ of Glioma Cells by $24 \mathrm{~h}$.

\begin{tabular}{|c|c|}
\hline Gliomas & LC50 of Cmpd10357 in $\boldsymbol{\mu M}$ \\
\hline PDX GBM 12 & 5 \\
\hline PDX GBM 39 & 5 \\
\hline PDX GBM 10 & 10 \\
\hline PDX GBM 38* & 10 \\
\hline PDX GBM 6 TMZ* & 10 \\
\hline HGG U87MG & 6 \\
\hline HGG LN229 & 8 \\
\hline HGG U118MG & 8 \\
\hline HGG U138MG & 8 \\
\hline Canine SB3TG & 4 \\
\hline Canine J3BTG & 5 \\
\hline Human primary astrocytes & $>100$ \\
\hline
\end{tabular}

*Temozolomide-resistant PDX glioma lines.

\section{Small molecules disrupt intracellular cytosolic and membrane uPA-PAI-1 complexes}

UCD38B and Cmpd10357 are cell permeant, competitive enzymatic inhibitors at the active site of uPA that is also competitively inhibited by the endogenous serpin PAI-1 [39]. PAI-1 is known to participate in the endosomal trafficking of urokinase proteins $[15,40]$. Therefore, we examined whether cell permeant UCD38B and Cmpd10357 triggered relocation of uPAS endosomes by disrupting intracellular uPA-PAI-1 complexes [30]. Whole cell extracts (total protein), cytosolic and membrane fractions were isolated to quantitatively measure by ELISA the uPA-PAI-1 protein content following drug treatments. Protein extracts were incubated with either UCD38B or Cmpd10357 for $1 \mathrm{~h}$ and $4 \mathrm{~h}$ at $37^{\circ} \mathrm{C}$. ELISA that was selective for uPA-PAI- 1 complexes quantified concentrations of uPA-PAI-1 complexes within the cellular and subcellular fractions (Table 3A \& 3B). The time intervals selected for quantification were basedupon observed endosomal resorting that begins 1 to 2 hours following drug incubation in four different HGG cell lines [30]. Cmpd10357 initiates endosomal resorting in the same time frame as UCD38B. Within 1h of drug incubation cytosolic uPA-PAI-1 content was reduced by nearly $50 \%$ and reduced by $70 \%$ by $4 \mathrm{~h}$. As anticipated, drug-induced depletion of uPA-PAI- 1 complexes associated with the intracellular membrane fractions occurred more slowly, (5\%, 50-60\%, at $1 \mathrm{~h}$ and $4 \mathrm{~h}$, respectively), reflecting uPAS endosomal relocation to endolysomes. Total intracellular uPA-PAI-1 protein content was reduced by $30 \%$ after $1 \mathrm{~h}$ and by 55 $60 \%$ after $4 \mathrm{~h}$, reflecting that drug incubation initially reduced cytosolic uPA-PAI-1 content that was followed by reduction in the intracellular membrane uPA-PAI-1 content.

Table 3A: Protein content of uPA-PAI-1 Complex within Glioma Cytosolic and Membrane fractions $1 \mathrm{~h}$ and $4 \mathrm{~h}$ after Cmpd10357 Administration.

\begin{tabular}{|c|c|c|}
\hline Protein Extracts & uPA-PAI-1 Complex in ng & \% Loss in uPA/PAI-1 Complex \\
\hline Untreated cytosol & 1.34 & 100 \\
\hline Untreated membrane & 7.64 & 50 \\
\hline Cmpd10357 cytosol, $1 \mathrm{~h}$ & 0.675 & 72 \\
\hline Cmpd10357 cytosol, $4 \mathrm{~h}$ & 0.371 & 6 \\
\hline Cmpd10357 membrane, $1 \mathrm{~h}$ & 7.21 & 54 \\
\hline Cmpd10357 membrane, $4 \mathrm{~h}$ & 3.48 & 5 \\
\hline
\end{tabular}


Open Access Journal of Neurology \& Neurosurgery

\begin{tabular}{|c|c|c|}
\hline UCD38Bcytosol, $1 \mathrm{~h}$ & 0.642 & 52 \\
\hline UCD38B cytosol, $4 \mathrm{~h}$ & 0.393 & 51 \\
\hline UCD38B membrane, $1 \mathrm{~h}$ & 7.28 & 61 \\
\hline UCD38B membrane, $4 \mathrm{~h}$ & 2.95 & 61 \\
\hline
\end{tabular}

Table 3B: Protein content of uPA-PAl-1 Complex in Whole cell protein extracts $1 \mathrm{~h}$ and $4 \mathrm{~h}$ after Cmpd10357 Administration.

\begin{tabular}{|c|c|c|}
\hline Intracellular Protein Extract & uPA-PAI-1 Complex in ng & \%Loss in uPA-PAI-1 Complex \\
\hline Untreated total protein & 3.32 & 31 \\
\hline Cmpd10357 treated, $1 \mathrm{~h}$ & 2.3 & 59 \\
\hline Cmpd10357 treated, $4 \mathrm{~h}$ & 1.36 & 30 \\
\hline UCD38B treated, $1 \mathrm{~h}$ & 2.33 & 56 \\
\hline
\end{tabular}

\section{Reduced expression of PAI-1 oruPA reduces the anti-glioma cytotoxicity of Cmpd10357 and UCD38B}

$\mathbf{A}$
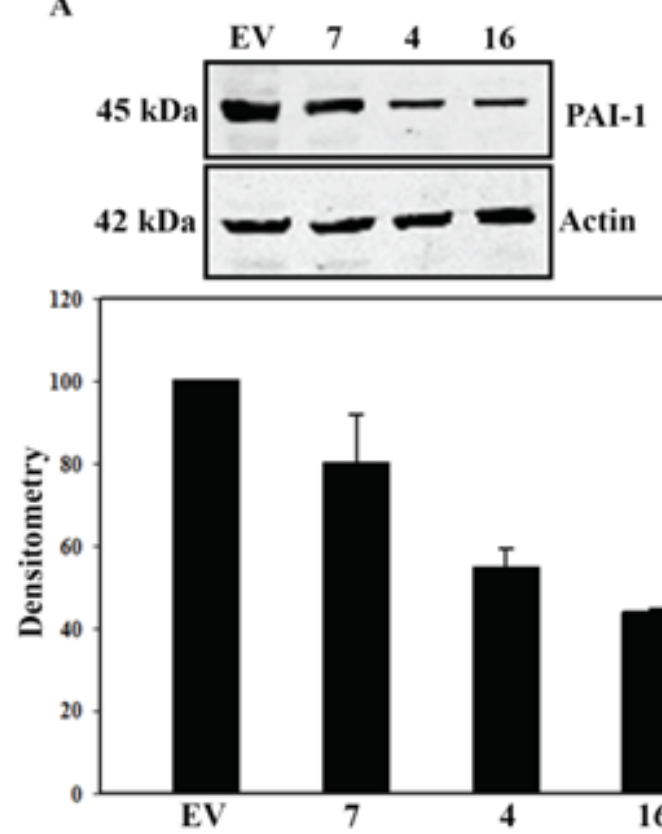

EV

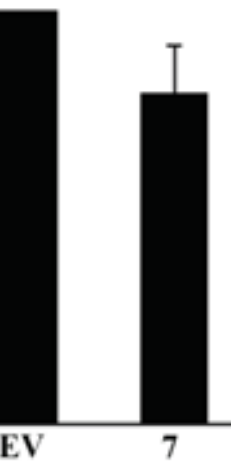

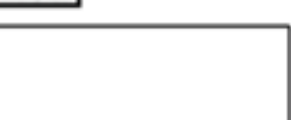

B

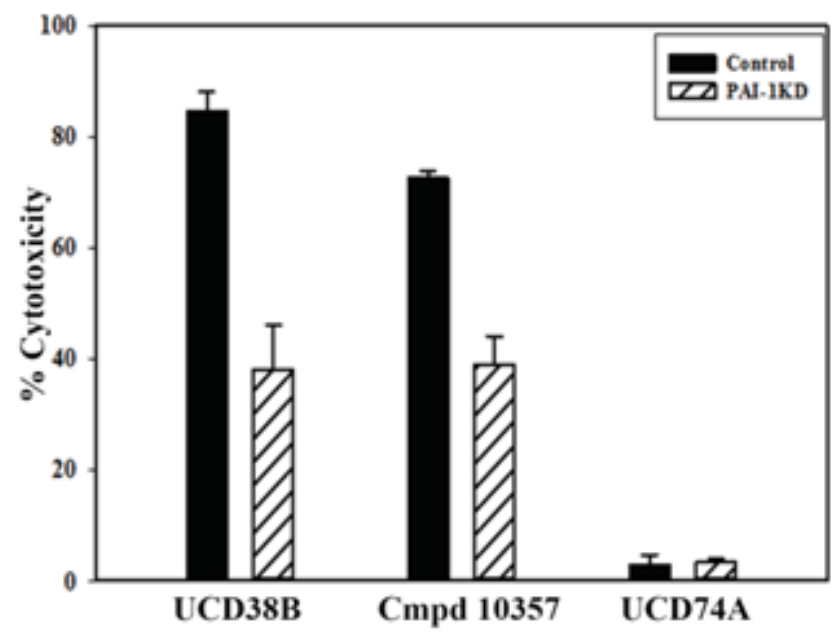

Figure 1: PAI-1 shRNA in U87 glioma cells associated with decrease cytotoxicities of Cmpd10357and UCD38B. Immunoblot of protein extracts from glioma cells stably transfected with PAI-1shRNA (clones 7, 4 and16)andwith empty vector control (EV). Reduced protein levels of PAI-1 were quantified by densitometry; normalized to actin as an internal control (A). Stably transfected clone 16 glioma cells expressing

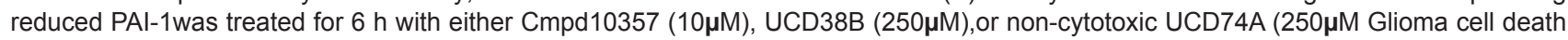
was measured using the LDH cytotoxicity assay(B). Results are presented as the mean \pm S.D. of $n=3$ with ${ }^{* *} P<0.001$. 
A
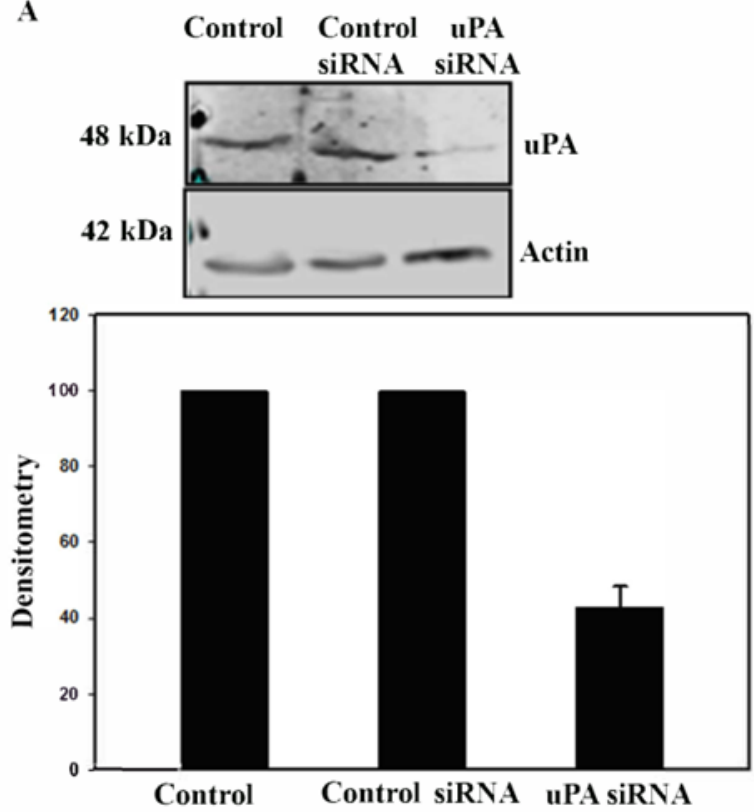

B

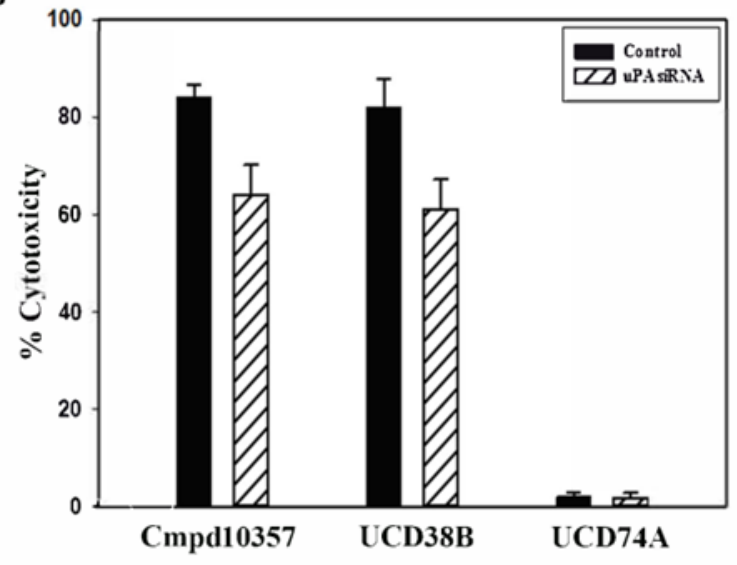

Figure 2: UPA siRNA in U87 glioma cells with decrease cytotoxicities of Cmpd10357and UCD38B. Immunoblot of protein extracts from glioma cells transfected with either UPA or controls iRNA. Reduced protein levels of uPA on days 4 and 5 were quantified by densitometry; normalized to actin as an internal control(A). Glioma cells on day 4 post transfection of uPA or control siRNA (control) were treated for $6 \mathrm{~h}$ with Cmpd10357 $(10 \mu \mathrm{M})$, UCD38B $(250 \mu \mathrm{M})$, or non-cytotoxic UCD74A $(250 \mu \mathrm{M}$. Cell death was determined by LDH cytotoxicity assay (B). Results are presented as the mean \pm S.D. of $n=3$ with ${ }^{* * *} P<0.001$.

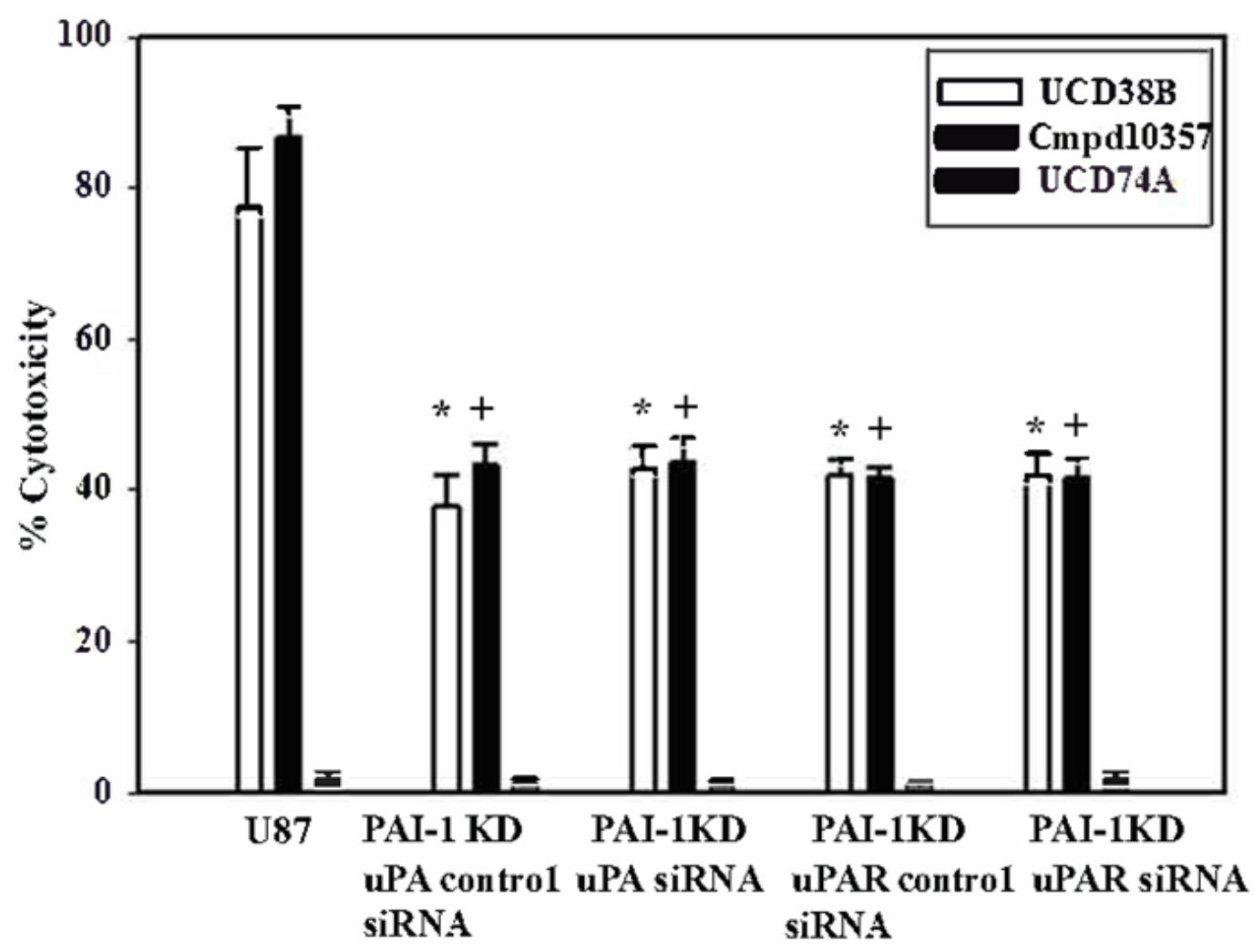

Figure 3: UPA and UPARsiRNA co-transfected in U87 glioma with reduced of PAl-1 expression. PAl-1 shRNAclone 16 was transfected with UPA or UPAR siRNA or both. On day 4 post-transfection, the cytotoxicities of Cmpd10357, UCD38B, and control UCD74A,were examined after $6 \mathrm{~h}$ exposure by LDH assay.Results are presented as the mean \pm S.D. of $n=3$ with ${ }^{* *} P<0.001$. 
Cmpd10357 causes relocation of uPAS endosomes and initiates release and nuclear translocation of apoptotic inducible factor (AIF)

Amiloride and other 5-position substituted amiloride derivatives, including hexamethyl amiloride (HMA) and ethyl isopropyl amiloride (EIPA) produce cancer cell death at 10to 100 -fold higher concentrations than Cmpd10357. Unlike 5'benzylglycinyl amiloride (UCD38B), neither amiloride nor HMA initiate uPAS endosomal trafficking and followed by AIFmediated necrosis [41,42]. Therefore, we investigated whether Cmpd10357, like UCD38B, initiated relocation of uPAS endosomes in LN229 human glioma cells that was followedwithin hours by
AIF nuclear translocation. When LN229 glioma cells were treated with Cmpd10357 for $1 \mathrm{~h}$, early endosomes that were co-stained with PAI-1 and EEA1 antibodies demonstrated relocation as we had reported for UCD38B [30] (Figure 4A). Previously, UCD38B had been demonstrated to cause IPAS endosomes to relocate to endolysosomes and perinuclear mitochondria [30]. This endosomal 'mis-trafficking' causes mitochondrial depolarization that is coupled to the release and nuclear translocation of AIF with resultant nuclear condensation and necrosis [30]. Here, we observed that $\mathrm{Cmpd} 10357(10 \mu \mathrm{M})$ similarly initiates early endosomal relocation followed by AIF nuclear translocation in LN229 glioma cells (Figure 4B).
A

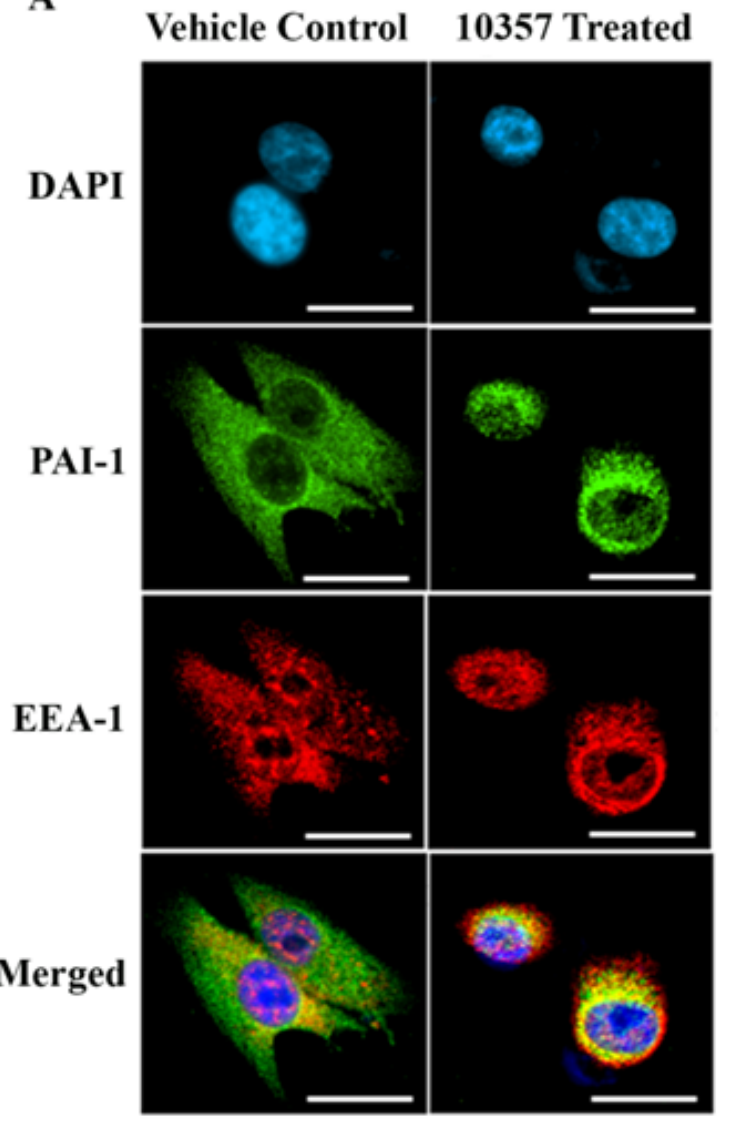

B

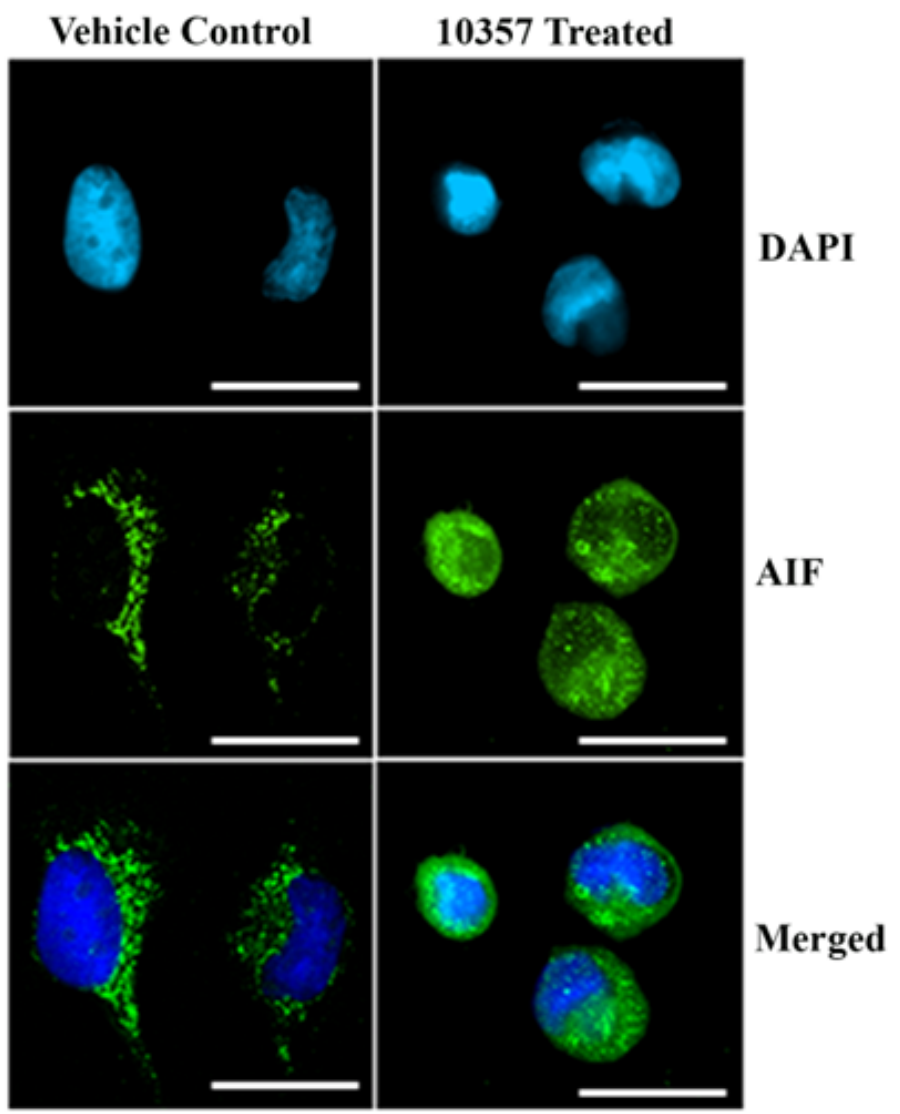

Figure 4: PAI-1 and AIF immunostaining in LN229 glioma cells.LN229 glioma cells were treated 2h with Cmpd10357 or vehicle DMSO. Glioma cells were immunostained for PAl-1 (green) and co-stained with an early endosomal marker EEA1 (red). Glioma cells treated $2 \mathrm{~h}$ with Cmpd10357 demonstrate perinuclear relocation of both PAI-1 and EEA1 (A). Glioma cells treated $2 \mathrm{~h}$ with $\mathrm{Cmpd} 10357$ or vehicle DMSO and immunostained for apoptotic inducible factor (AIF) (green) demonstrate nuclear translocation of apoptotic inducible factor (AIF) (B). Scale bar is $50 \mu \mathrm{m}, \mathrm{n}=3$. 


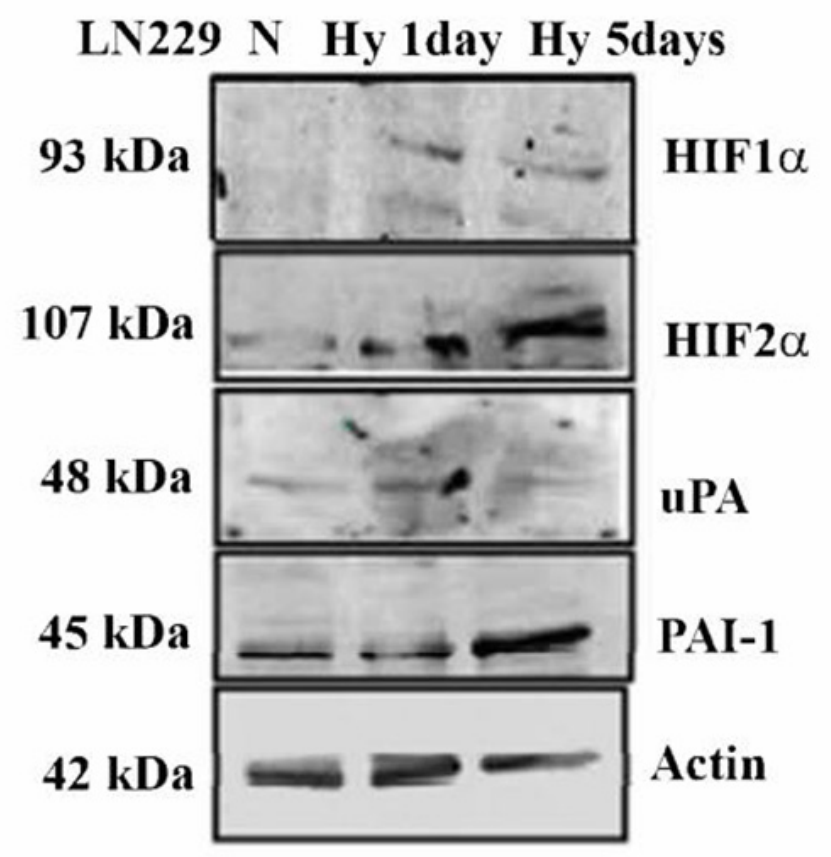

Figure 5: UPA and PAI-1 expression in LN229 human glioma cells under $1 \mathrm{~d}$ and $5 \mathrm{~d}$ of hypoxia $(0.5 \% \mathrm{O} 2 \mathrm{v} / \mathrm{v})$. Immunoblot were quantified and demonstrated increased protein expression of PAl-1 and uPA under $1 \mathrm{~d}$ and5d of hypoxia, $n=3$.

A

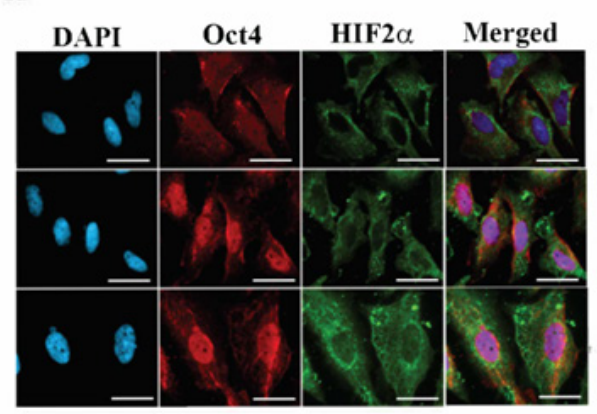

C

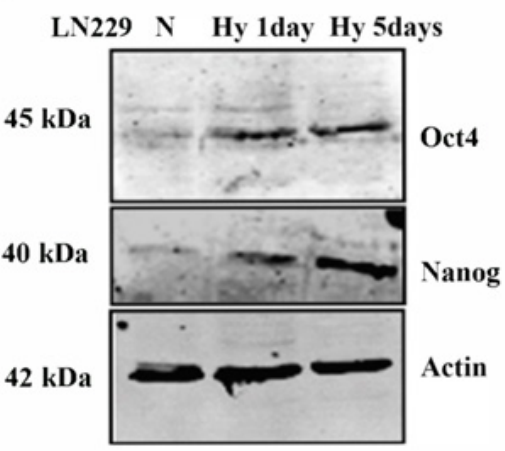

B

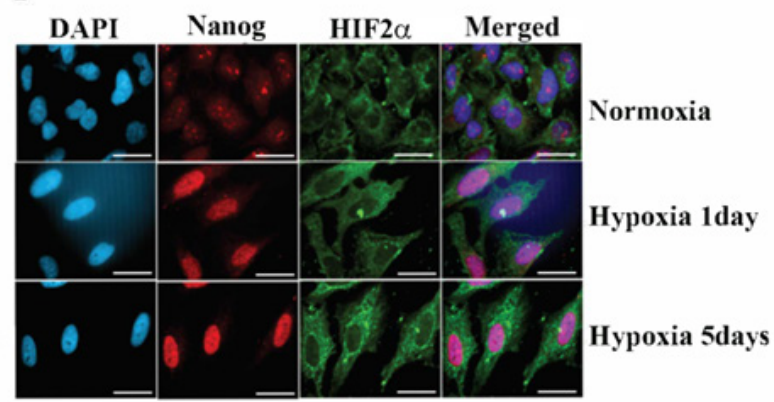

Figure 6: Oct4 and Nanog expression in LN229 human glioma cells under $1 \mathrm{~d}$ and $5 \mathrm{~d}$ of hypoxia $(0.5 \% \mathrm{O} 2 \mathrm{v} / \mathrm{v})$. Confocal fluorescent microscopy demonstrates protein expression of Oct4 and HIF2a(A),and Nanog and HIF2a(B) under $1 \mathrm{~d}$ and $5 \mathrm{~d}$ of hypoxia. Oct4 and Nanog were visualized as red using Alexa 594 secondary antibody. HIF2 $\alpha$ was visualized as green using Alexa 488 secondary antibody. Scale bar is $50 \mu \mathrm{m}$. Immunoblotting demonstrates increasing protein levels of Oct4 and Nanog, normalized to actin, with acute and persistent hypoxic conditions (C). Scale bar is $50 \mu \mathrm{m}, \mathrm{n}=3$. 


\section{Hypoxia increases expression of PAI-1 and UPA}

Increased levels of uPA expression correspond with increasing glioma grade $[32,43]$. Highly proliferative, solidcancer cell types prone to infiltration and metastasis express elevated levels of PAI-1 and UPA in hypovascularized and spontaneously perinecrotic tumor regions [34].Cmpd10357 targets and disrupts intracellular uPA-PAI-1 complexes, so that it was pertinent to determine the impact of acute and persistent hypoxia on PAI-1 and UPA expression in glioma cells. When LN229 glioma cell lines were maintained under hypoxia $(0.5 \% 02)$ for 1 day or 5 days, uPA expression increased following $24 \mathrm{~h}$ of hypoxia, temporally corresponding with increased HIF1 $\alpha$ expression (Figure 5). PAI1 expression increased approximately 3 -fold following 5 days of hypoxia that temporally corresponded with increased HIF $2 \alpha$ expression (Figure 5). These findings are consistent with other groups reporting that in human HGG cell lines HIF $2 \alpha$ activates the PAI-1 promoter to increase PAI-1 expression, while HIF1 $\alpha$ is associated with an increase in UPA expression [25].

\section{Hypoxia increases expression of Oct4 and Nanogin Human Glioma Cell Line}

Under hypoxia, HIF $2 \alpha$ has been demonstrated to activate promoters of the stem cell transcription factors Oct 4 , Nanog, and Sox2 [26-28]. Here, Oct4 and Nanog expression were examined in normoxic and hypoxic LN229 glioma cell linesas biomarkers of HIF $2 \alpha$ transcriptional reprogramming.Oct4 and Nanog expression is minimally expressed in normoxic LN229 glioma cells (Figure 6). When LN229 glioma cell lines were maintained under hypoxia $(0.5 \%$ 02) for 1 day or 5 days, Oct4 (Figure 6A) and Nanog (Figure 6B) stem cell markers were expressed in glioma cells as demonstrated by immunofluorescence and immunoblotting (Figure 6C).

\section{Embryonic transcription factors 0ct4 and Nanog are expressed in hypoxic tumor regions in PDX lines}

PDX glioma cells isolated from individuals with glioblastomas are passaged subcutaneously prior to intracerebral implantation in immunodeficient mice [35]. These PDX glioma explants have been reported to transfrom into glioma 'stem-like' cells (GSCs) [5,44]. Persistently hypoxic HGG tumor regions are reported to contain populations of glioma cells expressing the embryonic transcription factors Oct4 and Nanog [26]. We examined PDX glioma explant cell cultures plated for 10 days as recommended for the expression of stem cell markers Oct4 and Nanog using immunoblotting and immunofluorescence. Oct4 expression was observed in GBM12 and GBM39 both by immunoblotting and visualized in $60 \%$ of cells by fluorescent microscopy (Figure 7). In GBM10 PDX cells, Oct4 expression was not detected by immunoblotting (Figure 7A), but observed by immunofluorescence to be nuclearly expressed in $40 \%$ of GBM10 cells (Figure 7B). Nanog expression was observed in all the three PDX explant cell cultures both by immunoblotting and identified as nuclearly expressed by immunofluorescence. Nanog immmunostaining in GBM10 cells was less widespread than in GBM12 and GBM39 PDX cultures. 40\% of GBM10 cells expressed nuclear Nanog as verified by immunofluorecesce (Figure 7C). The brain sections from xenograft mice implanted with GBM12 PDX glioma cells were analogously immunostained for Oct4 and Nanog. Significantly, when GBM12 cells were implanted intracranially, less than $5 \%$ of cells immunostained for Nanog (Figure 7D). Oct4 was not be visualized in vivo by immune histochemistry.
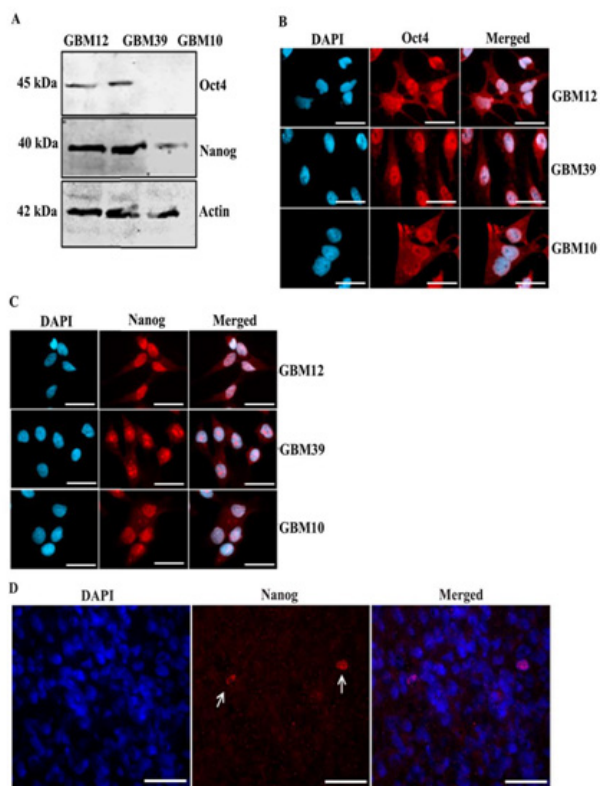

Figure 7: Embryonic transcription factors Oct4 and Nanog are expressed in PDX glioma cells. Immunoblot demonstrating Oct4 and Nanogprotein expressionin normoxic 10d cultures of the PDX glioma lines GBM10, GBM12 and GBM39. Protein expression was detected using anti-Oct4 and anti-Nanog polyclonal antibodies and actin as control (A). Immunofluorescence confocal microscopy identifies nuclear expression of Oct4 (B) and of Nanog(C). Immunohistochemistry demonstrating Nanogprotein expression in 5 micron glioma tumor sections from athymic mouse intracerebrally implanted with GBM12 cells (D).Scale bar is $50 \mu \mathrm{m}, \mathrm{n}=3$. 


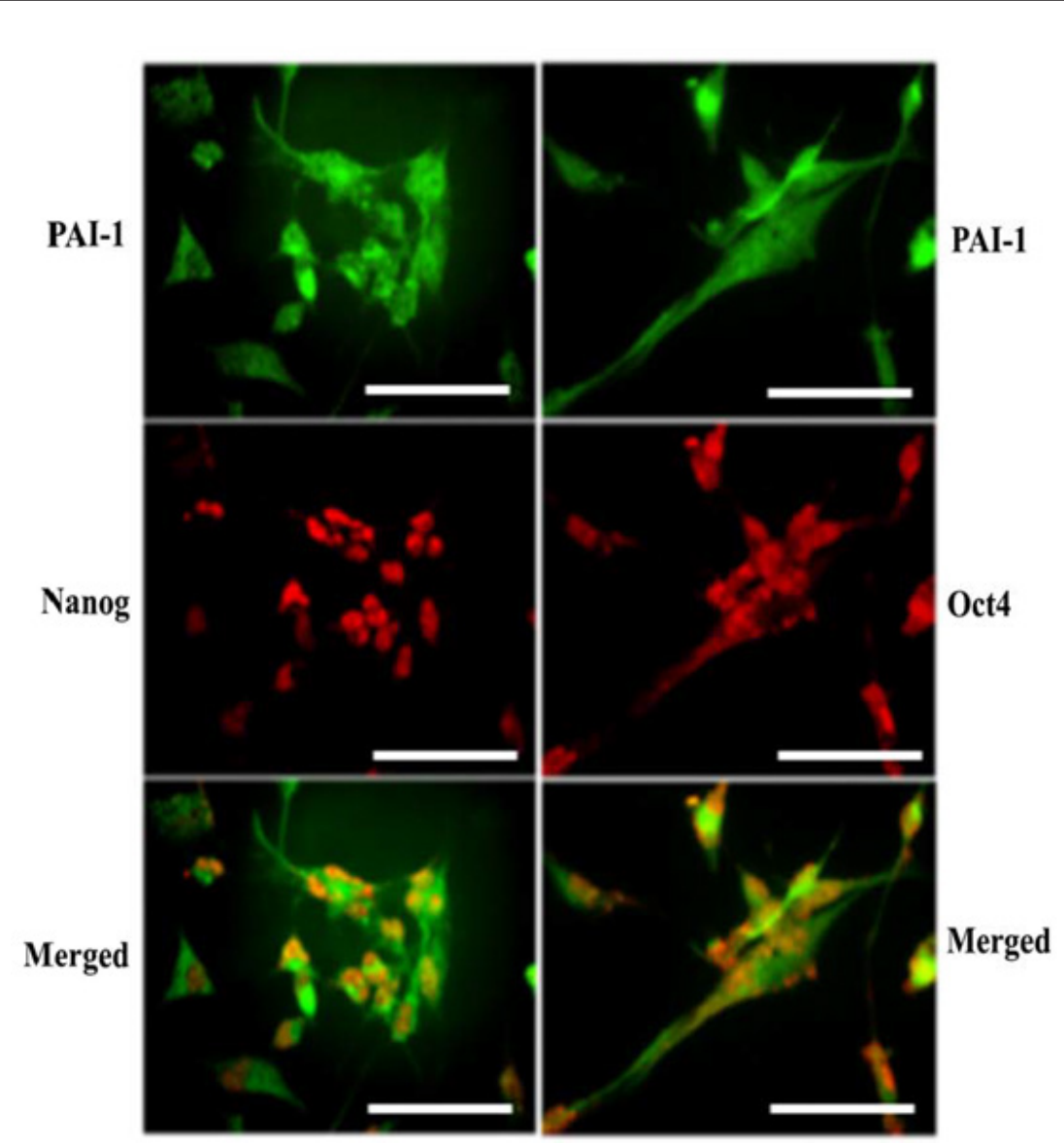

Figure 8: PAI-1 co-expression with the embryonic transcription proteins, Nanog and Oct4 in GBM 12 human glioma cells from patientderived xenograft (PDX). The experiments were repeated 3 times and scale bar is $50 \mu \mathrm{m}$.

PAI-1 is widely expressed in PDX glioma lines with a subset of cells co-expressing Nanog and Oct4

Employing a tissue microarray generated from 22 different PDX primary cultures [35,36], we observed that all PDX lines expressed intracellular PAI-1, as detected by immune histochemistry (Supplementary Figure 2) and summarized in Table 4. Importantly, PAI-1 expression was not observed in normal human or mouse brain tissues. In PDX GBM12, a subset of glioma cells expressing PAI-1 were identified to nuclearly coexpress the embryonic transcription proteins, Nanog and Oct 4 (Figure 8). PAI-1 expression in GBM12 is expressed in a much larger set of glioma cells expressing embryonic transcription factors.

Table 4: Expression of Plasminogen Activator Inhibitor Type 1 (PAI-1) in Normal Brain and in Glioma Cells from Intracerebral Patient-derived Xenografts (PDX).

\begin{tabular}{|c|c|}
\hline Tissue Type & PAI-1 IHC \\
\hline Human white matter & No \\
\hline Human grey matter & No \\
\hline Mouse basal ganglia & No \\
\hline Mouse cortex & No \\
\hline GBM5 & Yes \\
\hline GBM6 TMZ* & Yes \\
\hline GBM10 & Yes \\
\hline GBM12 & Yes \\
\hline GBM14 & Yes \\
\hline GBM16 & Yes \\
\hline GBM22 & Yes \\
\hline GBM26 & Yes \\
\hline
\end{tabular}




\section{Open Access Journal of Neurology \& Neurosurgery}

\begin{tabular}{|c|l|}
\hline GBM28 & Yes \\
\hline GBM34 & Yes \\
\hline GBM38* & Yes \\
\hline GBM39 & Yes \\
\hline GBM43 & Yes \\
\hline GBM44 & Yes \\
\hline GBM46 & Yes \\
\hline GBM59 & Yes \\
\hline
\end{tabular}

*Temozolomide-resistant PDX glioma lines.

\section{Cmpd10357 induces AIF nuclear translocation withinIntracerebral Glioma Xenografts}

We then examined whether in vivo administration of Cmpd10357 caused AIF nuclear translocation in PAI-1+glioma populations within intracerebral PDX glial tumors. Fifteen days following GBM 12 intracerebral implantation, animals were treated intraperitoneally (IP) for eight successive days with Cmpd10357 or $80 \%$ PEG400/20\% PBS vehicle, perfusion fixed, and immunostained for PAI-1. Immunohistostaining of the brain sections demonstrated that Cmpd10357 targeted PAI-1+ glioma cells and caused a transient reduction in glioma cell number $24 \mathrm{~h}$ after treatment (Figure 9A). Despite its evanescent nature, AIF nuclear translocation was confined to PAI-1+ glioma cell regions in GBM12 PDX intracerebral glioma xenografts when animals were treated subcutaneously with Cmpd10357 (10mg/kg/d IP) for $3 \mathrm{~d}$ and sacrificed $24 \mathrm{~h}$ later (Figure $9 \mathrm{~B}$ ). These collective in vivo results indicate that in vivoCmpd10357 activatesthe same AIF-mediated cell death mechanism of action by disrupting uPAPAI-1 leading to transient diminution of PAI-1+ glioma cells with AIF-mediated cell death identified in the treated tumors.

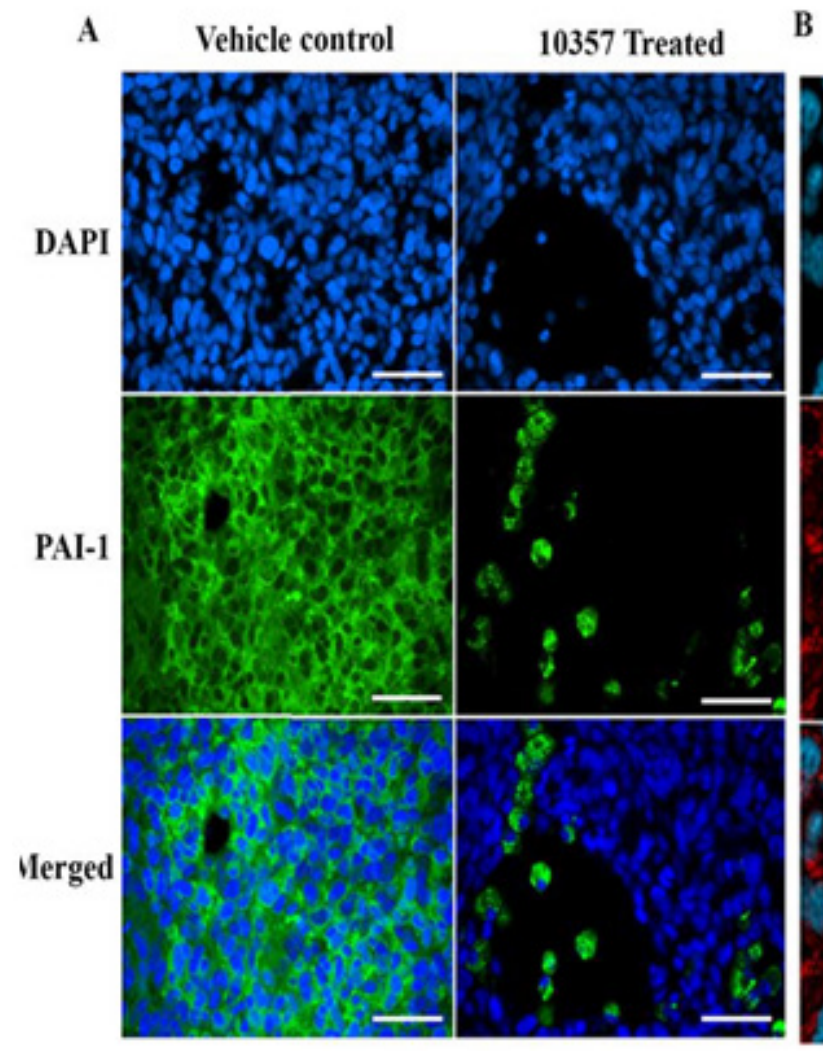

B Vehicle control

10357 Treated

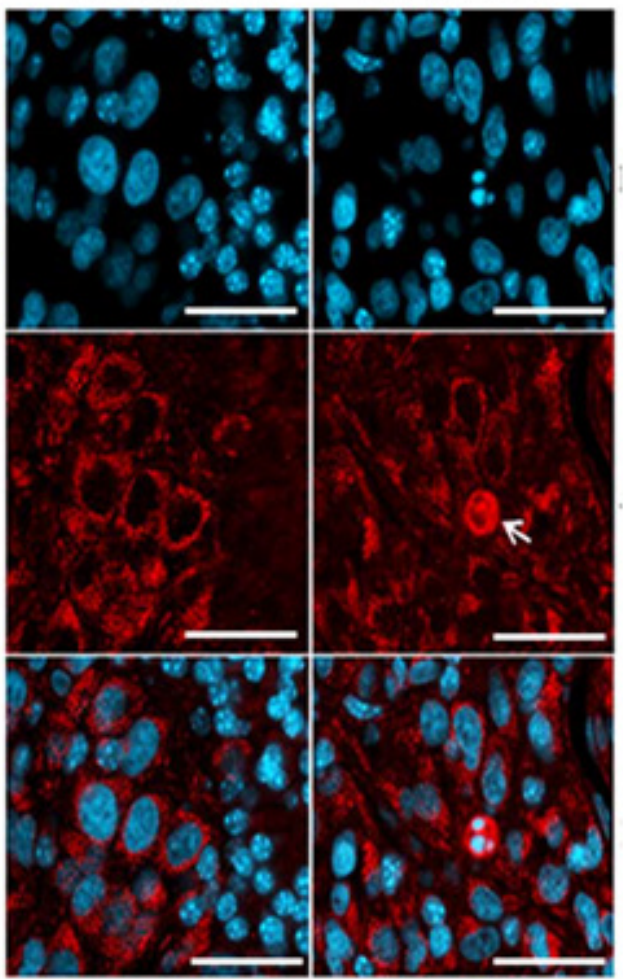

DAPI

AIF

Merged

Figure 9: PAI-1 and AIF immunostaining within PDX intracerebral glioma xenografts.Immunohistochemistry of brain sections $(5 \mu)$ from athymic mice xenografts implanted intracrebrally with GBM12 PDX glioma cells. Animals were treated with $\mathrm{Cmpd} 10357 \mathrm{at} 10 \mathrm{mg} / \mathrm{kg} /$ day (IP) or with $80 \%$ PEG400/20\% PBS (vehicle control) for 8 consecutive days and sacrificed $24 \mathrm{~h}$ following the last treatment. Nuclei were stained with DAPI (blue) and demonstrated cytoplasmic expression of PAl-1 (green) (A). Animals were treated with subcutaneous Cmpd10357 (10mg/kg/d IP) for 3days and harvested 48h post final treatment. Nuclei were stained with DAPI (blue) and AIF (red). Nuclear translocation of AIF was identified by confocal microscopy only in tumor regions of animals treated with Cmpd10357 but not controls (B). Scale bar is $50 \mu \mathrm{m}, \mathrm{n}=3$. 


\section{Open Access Journal of Neurology \& Neurosurgery}

\section{Discussion}

High grade gliomas (HGGs) are primary CNS cancers with more than $95 \%$ of patients demonstrating tumor recurrence following radiation therapy, chemotherapy, and/or an antiangiogenic therapy. The high recurrence rate is a consequence of populations of glioma initiating cells (GICs) with subpopulations expressing embryonic "stem-like" biomarkers (GSCs) [26,27,45]. Our group and others have reported that acidosis associated with hypoxia in perinecrotic and hypovascularized tumor domains slow or completely inhibit proliferation of GICs fostering their resistance to anti-mitotic agents in addition to ineffectiveness of radiation therapy [46]. GICs and GSCs persist in avascular or hypovascularized tumor microenvironments making it difficult to deliver macromolecules, including monoclonal antibodies, directed against GSCs. Agents targeting these hypoxic, nonproliferative GICs and GSCs optimally should be irreversibly cytotoxic and utilize cell death mechanisms independent of cell cycle progression. Populations of hypoxic GICs and GSCs can be small and scattered through microenvironments of infiltrating HGGs so that agents targeting hypoxically transformed glioma cells will most likely be used in conjunction with conventional therapies and potentially anti-angiogenic therapies.

Cmpd10357, a small molecule 20-fold more potent than UCD38B permitted delineation of intracellular protein complex UPA-PAI-1 as the putative drug target causing cell-cycle independent glioma demise by triggering 'mis-trafficking' of uPAS endosomes. Its parent compound, UCD38B (Table 1) [47] is glioma cytotoxic via an AIF-mediated, caspase-independent, necrotic cell death [29]. The anti-glioma cytotoxicity of UCD38B required that the small molecule be cell permeant and competitively inhibit uPA enzymatic activity [33,34]. UCD38B, but not its cell impermeant homolog UCD74A, was demonstrated in four distinct HGG cell lines to initiate relocation of $40-60 \%$ of uPAS endosomes to perinuclear mitochondria and to endolysosomes [30] (Table 1). Inhibition of endosomal trafficking by cooling to $0{ }^{\circ} \mathrm{C}$ glioma cells treated with UCD38B for $2 \mathrm{~h}$, prevented cell death until the washed cells were rapidly rewarmed to $37^{\circ} \mathrm{C}$ to restart trafficking with resultant glioma cell death [30]. Neither amiloride [41] or hexamethyl amiloride (HMA) cause endosomal trafficking or its associated AIFmediated necrosis [42].

The enhanced potency of Cmpd10357 permitted intracellular target validation using a commercial ELISA specific for PAI-1uPA complex. Like UCD38B, Cmpd10357 is capable of rapidly disrupting intracellular uPA-PAI-1 complexes, whichtemporally corresponds with drug-induced relocation of uPAS endosomes [30]. Cmpd10357 and UCD38B initiate relocation of uPAS endosomes within 1 to $2 \mathrm{~h}$ of incubation (Figure $4 \mathrm{~A}$ ). Druginduced endosomal relocation temporally corresponds with the $50 \%$ reduction in cytosolic uPA-PAI- 1 following $1 \mathrm{~h}$ drug exposure (Table 3A). After four hours, total cellular uPA-PAI-1 content is reduced by $59 \%$ (Table $3 \mathrm{~B}$ ) corresponding with a marked loss uPA- PAI-1 content in the intracellular membrane fraction (50-60\%) with additional loss of cytosolic content $(70 \%)$ (Table 3A). This reduction in the intracellular membrane fraction corresponds with the relocation of UPAS endosomes to endolysomes and perinuclear mitochondria following treatment [30].

Gene silencing experiments were employed to individually and jointly reduce the expression of uPA and PAI-1 to additionally confirm that PAI- 1 and uPA dually contribute to the anti-glioma cytotoxicities of Cmpd10357 and UCD38B. Gene silencing studies using shRNA and siRNA transfection downregulated the protein expression of PAI-1, uPA and UPAR in U87 gliomacells by approximately $60 \%$. The cytotoxicities of Cmpd10357 and UCD38Bwere reduced by approximately 50\% in PAI-1 knockdown glioma cells but remained unaffected by reducinguPAR expression. Cytotoxic potencies of Cmpd 10357 or UCD38B were not further reduced by co-transfecting either UPA or UPAR siRNA into clonal glioma cells that had been stably transfected with PAI-1 shRNA. The lack of additivity observed in the co-transfection experiments are consistent with the idea that UCD38B and Cmpd 10357 target both uPA and PAI-1 through a common intracellular mechanism. Gene inactivation of PAI-1 by CRISPR/cas 9 caused glioma cell detachment and demise of detached cells over several days (data not shown). The ELISA and partial gene inactivation studies are consistent with the proposed drug mechanism that these small molecules act by displacing PAI-1 bound to the active site of UPA. The endosomal guidance protein LRP-1 was shown by Andreasen \& colleagues [14] to bind to common protein regions shared by UPA and PAI1 at the binding site of UPA-PAI-1 [14]. LRP-1 is an endosomal guidance protein that participates in endocytosis of the PAI1-uPA::uPAR complex at the plasmalemma and internalized as a quaternary complex guiding uPAS endosomal trafficking $[14,48]$. The proposed drug target (UPA-PAI-1) and the observed 'mis-trafficking' of uPA endosomes by Cmpd10357 and UCD38B differs from other plasmalemmal UPA and PAI-1 antagonists and from anti-cancer cytotoxic mechanisms described for amiloride [41] and hexamethyl amiloride (HMA) [42]. Cmpd10357, like its parent compund UCD38B, also triggered early endosomal relocation follwoed by AIF nuclear translocation in LN229 glioma cells.

PAI-1 is not expressed in normal adult brain or vascular cell types [8,23], while UPA and PAI-1 expression is elevated in high grade glioma (HGG) cells within perinecrotic and hypoxic HGG tumor microenvironments $[32,49,50]$. In this report, we identify that persistent hypoxia significantly increases PAI1 expression in a human glioma cell line, and confirm that acute hypoxia additionally increases uPA. Expression of uPAPAI-1 is employed as a clinical biomarker to predict increased propensity for metastasis and recurrence of a number of solid, highly proliferative cancers, most notably lymph node negative breast cancers [12,13]. Disrupting intracellular uPA-PAI-1 by Cmpd10357 or by UCD38B triggers irreversible, caspaseindependent, necrotic cell death mediated by AIF in high grade 


\section{Open Access Journal of Neurology \& Neurosurgery}

glioma cell lines and in multiple breast cancer cell lines [29,31].

The selective cancer cell cytotoxicity associated with disrupting this intracellular protein complex suggests a potential functional importance of intracellular uPA-PAI-1 in maintaining the survival of detached cancer cells that can then metastasize [51]. Consequently, it was important to examine whether acute and persistent hypoxia regulated the expression of PAI-1 and embryonic transcription factors in clonal LN229 and inPDX glioma cell lines. PDX glioma lines are genetically heterogenous between the different lines [52] and in this investigation demonstrate heterogenous expression of embryonic transcription factors. Therefore, it was important to evaluate the effect of hypoxic conditions on the genetically validated and homogenous LN229 human glioma cell line (ATCC® CRL-2611)[37]. uPA expression has also been shown to correspond with increasing grades of astrocytomas [43]. uPA expression is present in normoxic LN229 glioma cells and increases with acute hypoxia. Persistent hypoxia via HIF $2 \alpha$ directly upregulates the expression of additional potential glioma drug targets, including PAI-1 resulting in the formation of plasmalemmal and intracellular uPA-PAI-1 protein complexes [53]. PAI-1 expression increased more markedly (3fold) in human LN229 cells that remained hypoxic $(0.5 \% 02 \mathrm{v} / \mathrm{v})$ for $5 \mathrm{~d}$. Oct4 and Nanog stem cells markers were not detected in normoxic LN229 cells, but expressed when maintained under hypoxic conditions that temporally corresponded with the increase in HIF2 $\alpha$ expression (Figure 6).

PAI-1 cellular expression was identified in a panel of 22 different PDX cell lines on a tissue microarray and not in normal

Supplementary Table 1: Pharmaco distribution of subcutaneously administered compound 10357.

\begin{tabular}{|c|c|}
\hline Pharmaco Distribution of Cmpd10357 in Male SD Rats & \\
\hline Plasma Half-Life & $21 \mathrm{~h}$ \\
\hline Brain Half-Life & $16 \mathrm{~h}$ \\
\hline Brain/Plasma Ratio & $1: 10$ \\
\hline Volume of distribution (273 g rat) & \\
\hline Clearance (273 g rat) & $7.7 \mathrm{~L}$ \\
\hline
\end{tabular}

brain regions. In GBM12, GBM39 and GBM10 PDX gliomas, and Nanog, were identified in subset of glioma cells. Oct4 and Nanog was expressed in $40-60 \%$ of glioma cells within normoxic GBM12, GBM39 and GBM10 PDX lines (Figure 7). However, only a few GBM12 cells $(<5 \%)$ were identified as continuing to express perinuclear Nanog 15 days post intracerebral implantation. Oct4 expression was not identified by confocal fluorescent microscopy. This suggests that other glioma initiating cellsreplicate more rapidly within these intracerebral glioma xenografts than hypoxically reprogrammed, GSCs [54].

Because Cmpd10357 crosses the blood brain barrier (Supplementary Table 1), it was possible in this report to demonstrate that drug-induced AIF nuclear translocation occurred within treated intracerebral xenografts. AIF mitochondrial release and its nuclear translocation occurs within hours of drug-induced uPAS endosomal relocation and is rapidly accompanied by nuclear condensation and glioma necrosis [29]. Because of its evanescence, AIF nuclear translocation was detected in scattered glioma cells within a field of PAI-1+ glioma cells in treated xenografts (Figure 8D). Subcutaneously administered Cmpd10357 caused transient reductions of PAI-1+ glioma cells only when visualized $24 \mathrm{~h}$ following treatment (Figure 8C). Bioluminescent imaging identified that luciferase-transfected GBM12 intracerebral xenografts treated with subcutaneous Cmpd10357 transiently reduced tumor bioluminescence for $24-48 \mathrm{~h}$ and was followed by a rapid increase in total tumor biolumenscence (data not shown). co-expression of stem cell transcription factor proteins, Oct4 


\section{Open Access Journal of Neurology \& Neurosurgery}

It is likely that dying hypoxic PAI-1+ glioma cells targeted by Cmpd10357 are quickly replaced by more rapidly proliferating normoxic GBM12 glioma cells (data not shown). This reinforces the requirement for agents targeting hypoxic GICs and GSCs to be used in combination with anti-mitotic and other conventional anti-glioma therapies. Encouragingly, Cmpd10357 is cytotoic to temozolamide-resistant PDX glioma lines suggesting that disrupting intracellular uPA-PAI-1 complex may have clinical utility in targeting quiescent cancer cells residing in hypoxicischemic environments (Supplementary Figure 1).

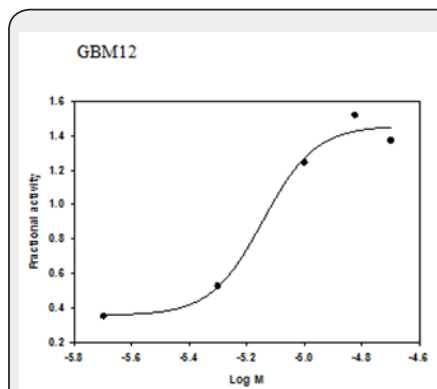

GBM10

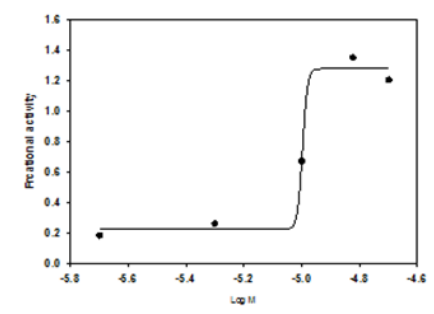

GBM39

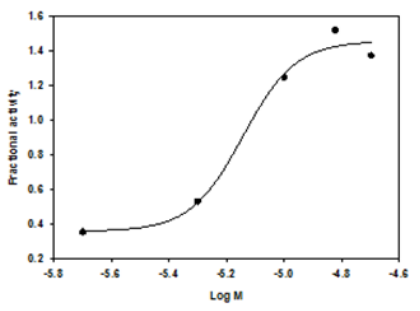

GBM38* (Temozolomide Resistant)

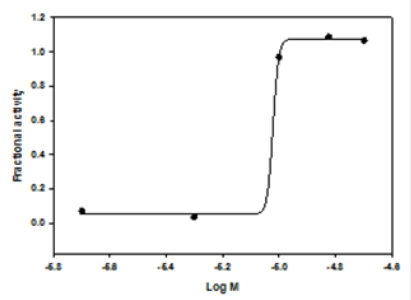

GBM 6 TMZ (Temozolomide Resistant)

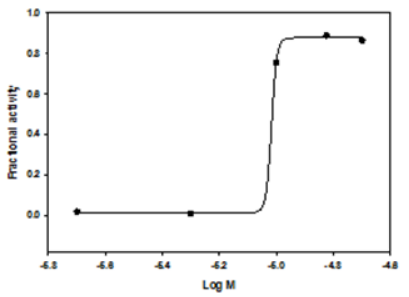

Human LN229 glioma line

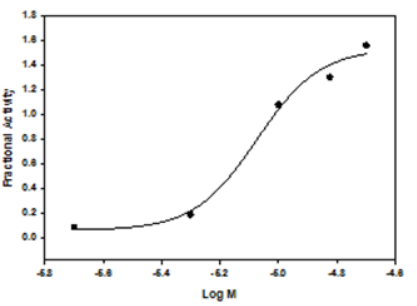

Human U87MG glioma line

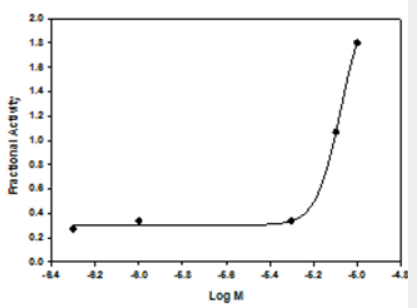

Human U118MG glioma line

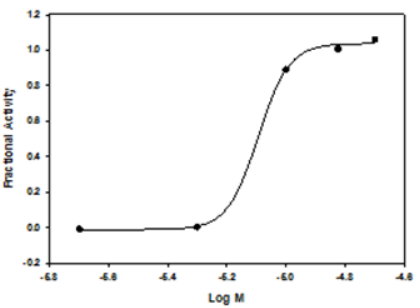

Human U138MG glioma line

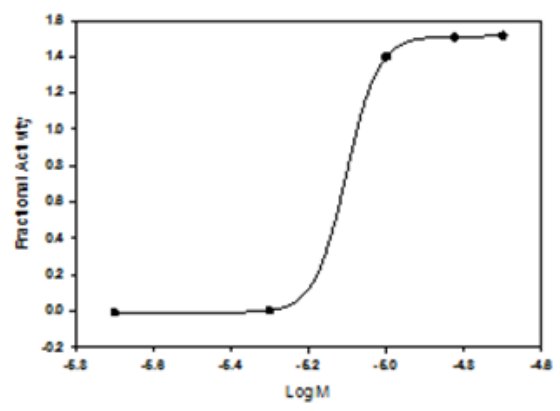

Canine J3BTG glioma line

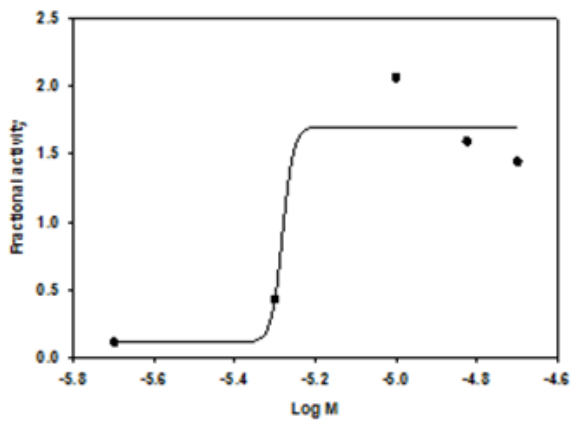

Canine SB3 TG glioma line

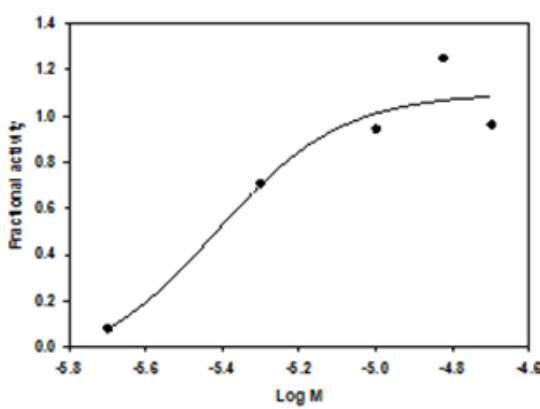

Supplementary Figure 1: Concentration Cytoxicity of Cmpd10357 in PDX Glioma and Human Glioma Cell lines: Cell death was determined by LDH cytotoxicity assay. Glioma cell were treated with $\mathrm{Cmpd} 10357$ at $10 \mu \mathrm{M}$ for $24 \mathrm{~h}$ or DMSO vehicle $(0.1 \%)$ and cell death was determined by LDH assay. The graphs were generated using Sigma Stat software version 2.00 (SPSS Science Inc, Chicago, IL). 


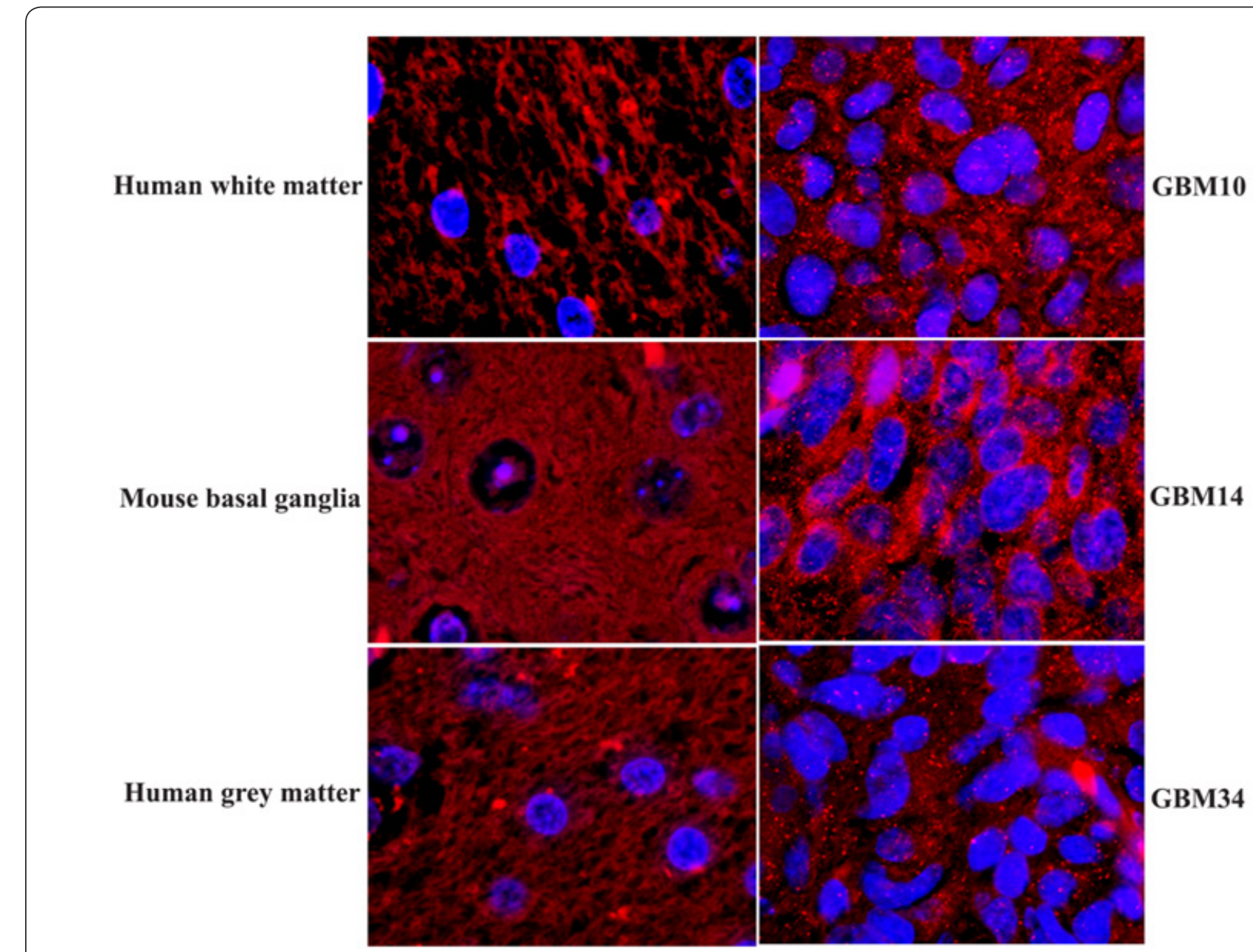

Supplementary Figure 2: PAI-1 expression in PDX glioma cells: Representative images demonstrating expression of PAI-1 (red) on a tissue array with different PDX glioma cells was demonstrated by immunohistochemistry using Alexa 594 secondary antibody.

\section{Author Contributions}

Gorin and Pasupuleti designed and conducted the referenced drug mechanism of action studies and co-wrote this article. Dinesh Mahajan, Sphaera Pharma Pvt. Ltd, synthesized and characterized the small molecules described in this review.

\section{Conflict of Interest}

Fredric Gorin is the founder and scientific advisor of D3G Inc, a company that identifies novel anti-cancer small molecules. Sundeep Dugar is the founder and CEO of Sphaera Pharma is an integrated drug discovery and development organization in India, Singapore and the US, to bridge innovation, resources and expertise in a collaborative model to develop novel therapies.

\section{Funding}

The National Institutes of Health, Neurological Sciences (Grants R01-NS040489 and R01-NS060880), the University of California Davis School of Medicine, and the University of California Davis Research Investments in Science and Engineering (RISE) funded this research.

\section{Acknowledgement}

The UC Regents and Gorin and Nantz patented UCD38B [45]. F. Gorin and S. Dugar co-invented additional small molecules targeting intracellular uPA-PAI-1, including 5'arylamino pyrazine-2-carboximide, Compound 10357, UCD38B, and UCD74A. UC Davis is an accredited AAALAC facility (\#000029) currently operating underPHS Animal Assurance \#A3433-01. Animal housing, handling, and procedures were institutionally reviewed and approved as described in IACUC protocol \#19401.

\section{References}

1. Clarke MF, Dick JE, Dirks PB, Eaves CJ, Jamieson CH, et al. (2006) Cancer stem cells--perspectives on current status and future directions: AACR Workshop on cancer stem cells. Cancer Res 66(19): 9339-9344.

2. Vasudev NS, Reynolds AR (2014) Anti-angiogenic therapy for cancer: current progress, unresolved questions and future directions. Angiogenesis 17(3): 471-494.

3. Jackson MF, Hassiotou, Nowak A (2015) Glioblastoma stem-like cells: at the root of tumor recurrence and a therapeutic target. Carcinogenesis 36(2): 177-85.

4. Gorin F, William H, Joachim S, Bruce L, Thomas J (2004) Perinecrotic glioma proliferation and metabolic profile within an intracerebral tumor xenograft. Acta Neuropathologica, 107(3): 235-244. 


\section{Open Access Journal of Neurology \& Neurosurgery}

5. Lee G, Auffinger B, Guo D, Hasan T, Deheeger M, et al. (2016) Dedifferentiation of glioma cells to glioma stem-like cells by therapeutic stress-induced HIF signaling in the recurrent GBM model. Mol Cancer Ther 15(12): 3064-3076.

6. Colwell N, Larion M, Giles AJ, Seldomridge AN, Sizdahkhani S, et al. (2017) Hypoxia in the glioblastoma microenvironment: shaping the phenotype of cancer stem-like cells. Neuro Oncol 19(7): 887-896.

7. Liebelt BD, Takashi S, Xin Z, Jiangong R, Seul AS, et al. (2016) Glioma Stem Cells: Signaling, Microenvironment, and Therapy. Stem Cells Int doi: 10.1155/2016/7849890.

8. Muracciole X, Romain S, Dufour H, Palmari J, Chinot O, et al. (2002) PAI1 and EGFR expression in adult glioma tumors: toward a molecular prognostic classification. Int J Radiat Oncol Biol Phys 52(3): 592-598.

9. Yamamoto M, Sawaya R, Mohanam S, Loskutoff DJ, Bruner JM, et al. (1994) Expression and cellular localization of messenger RNA for plasminogen activator inhibitor type 1 in human astrocytomas in vivo. Cancer Res 54(13): 3329-3332.

10. Raghu H (2011) Specific knockdown of uPA/uPAR attenuates invasion in glioblastoma cells and xenografts by inhibition of cleavage and trafficking of Notch -1 receptor. Mol Cancer 10: 130.

11. Harbeck N, Schmitt M, Meisner C, Friedel C, Untch M, et al. (2013) Ten-year analysis of the prospective multicentre Chemo-N0 trial validates American Society of Clinical Oncology (ASCO)-recommended biomarkers UPA and PAI-1 for therapy decision making in nodenegative breast cancer patients. Eur J Cancer 49(8): 1825-1835.

12. Schmitt M, Mengele K, Napieralski R, Magdolen V, Reuning U et al. (2010) Clinical utility of level-of-evidence-1 disease forecast cancer biomarkers uPA and its inhibitor PAI-1. Expert Rev Mol Diagn 10(8): 1051-1067.

13. Kantelhardt EJ, Vetter M, Schmidt M, Veyret C, Augustin D, et al. (2011) Prospective evaluation of prognostic factors uPA/PAI-1 in node-negative breast cancer: phase III NNBC3-Europe trial (AGO, GBG, EORTC-PBG) comparing 6xFEC versus $3 \mathrm{xFEC} / 3 \mathrm{xD}$ ocetaxel. BMC Cancer 11: 140 .

14. Skeldal S, Larsen JV, Pedersen KE, Petersen HH, Egelund R, et al. (2006) Binding areas of urokinase-type plasminogen activator-plasminogen activator inhibitor-1 complex for endocytosis receptors of the lowdensity lipoprotein receptor family, determined by site-directed mutagenesis. FEBS J 273(22): 5143-59.

15. Andreasen PA, Sottrup JL, Kjøller L, Nykjaer A, Moestrup SK, et al. (1994) Receptor-mediated endocytosis of plasminogen activators and activator/inhibitor complexes. FEBS Lett 338(3): 239-245.

16. Wilson, WR, Hay MP (2011) Targeting hypoxia in cancer therapy. Nat Rev Cancer 11(6): 393-410.

17. Vaupel P (2004) The role of hypoxia-induced factors in tumor progression. Oncologist 9(5): 10-17.

18. Pouyssegur J, Dayan F, Mazure NM (2006) Hypoxia signalling in cancer and approaches to enforce tumour regression. Nature 441(7092): 437443.

19. Eales, KL, KE Hollinshead, Tennant DA (2016) Hypoxia and metabolic adaptation of cancer cells. Oncogenesis 5: 190

20. Shimizu M, Cohen B, Goldvasser P, Berman H, Virtanen C, et al. (2011) Plasminogen activator uPA is a direct transcriptional target of the JAG1-Notch receptor signaling pathway in breast cancer. Cancer Res 71(1): 277-286

21. Hofbauer KH, Gess B, Lohaus C, Meyer HE, Katschinski D, et al. (2003) Oxygen tension regulates the expression of a group of procollagen hydroxylases. Eur J Biochem 270(22): 4515-4522.
22. Noda T, Yamamoto H, Takemasa I, Yamada D, Uemura M, et al. (2012) PLOD2 induced under hypoxia is a novel prognostic factor for hepatocellular carcinoma after curative resection. Liver Int 32(1): 110-118.

23. Rao JS, Rayford A, Morantz RA, Festoff BW, Sawaya R (1993) Increased levels of plasminogen activator inhibitor-1 (PAI-1) in human brain tumors. Journal of Neuro-Oncology 17(3): 215-221.

24. Meade ES, Ma YY, Guller S (2007) Role of hypoxia-inducible transcription factors 1 alpha and 2alpha in the regulation of plasminogen activator inhibitor-1 expression in a human trophoblast cell line. Placenta 28(10): 1012-1019.

25. Ahn YT, Chua MS, Whitlock JP, Shin YC, Song WH (2010) Rodentspecific hypoxia response elements enhance PAI-1 expression through HIF-1 or HIF-2 in mouse hepatoma cells. Int J Oncol 37(6): 1627-1638.

26. Bache M, Rot S, Keßler J, Güttler A, Wichmann H, et al. (2015) mRNA expression levels of hypoxia-induced and stem cell-associated genes in human glioblastoma. Oncol Rep 33(6): 3155-3161.

27. Petruzzelli R, Christensen DR, Parry KL, Sanchez Elsner T, Houghton FD (2014) HIF-2 $\alpha$ regulates NANOG expression in human embryonic stem cells following hypoxia and reoxygenation through the interaction with an Oct-Sox cis regulatory element. PLoS One 9(10): e108309.

28. Covello KL, Kehler J, Yu H, Gordan JD, Arsham AM, et al. (2006) HIF$2 \alpha$ regulates Oct- 4 : effects of hypoxia on stem cell function, embryonic development, and tumor growth. Genes Dev 20(5): 557-570.

29. Pasupuleti N, Leon L, Carraway KL, Gorin F (2013) 5-Benzylglycinylamiloride kills proliferating and nonproliferating malignant glioma cells through caspase-independent necroptosis mediated by apoptosisinducing factor. J Pharmacol Exp Ther 344(3): 600-615.

30. Pasupuleti N, Grodzki AC, Gorin F (2015) Mis-trafficking of endosomal urokinase proteins triggers drug-induced glioma nonapoptotic cell death. Mol Pharmacol 87(4): 683-696.

31. Leon LJ, Pasupuleti N, Gorin F, Carraway KL, et al. (2013) A cellpermeant amiloride derivative induces caspase-independent, AIFmediated programmed necrotic death of breast cancer cells. PLoS One 8(4): e63038.

32. Hsu DW, Efird JT, Hedley Whyte ET (1995) Prognostic role of urokinasetype plasminogen activator in human gliomas. Am J Pathol 147(1): 114-123.

33. Massey AP, William R Harley, NagaRekha Pasupuleti, Fredric A Gorin, Michael H, et al. (2012) 2-Amidino analogs of glycine-amiloride conjugates: inhibitors of urokinase-type plasminogen activator. Bioorg Med Chem Lett 22(7): 2635-2639.

34. Gorin FA, Pasupuleti N, Mahajan D, Dugar S (2017) Killing Glioma 'Stem-like' Cells via Drug-Induced Relocation of Endosomal Urokinase Proteins. Anticancer Agents Med Chem 17(1): 40-47.

35. Sarkaria JN, Carlson BL, Schroeder MA, Grogan P, Brown PD, et al (2006) Use of an orthotopic xenograft model for assessing the effect of epidermal growth factor receptor amplification on glioblastoma radiation response. Clin Cancer Res 12(7 Pt 1): 2264-2271.

36. Sarkaria JN, Lin Yang, Patrick T Grogan, Gaspar J Kitange, Brett L Carlson et al. (2007) Identification of molecular characteristics correlated with glioblastoma sensitivity to EGFR kinase inhibition through use of an intracranial xenograft test panel. Molecular Cancer Therapeutics 6(3): 1167-1174.

37. (ATCC), A.T.C.C. LN229 Tissue Culture characterization (ATCC® CRL$\left.2611^{\mathrm{TM}}\right)$

38. Kitange GJ, Carlson BL, Mladek AC, Decker PA, Schroeder MA, et al. (2009) Evaluation of MGMT promoter methylation status and 


\section{Open Access Journal of Neurology \& Neurosurgery}

correlation with temozolomide response in orthotopic glioblastoma xenograft model. J Neurooncol 92(1): 23-31.

39. Andreasen PA (2007) PAI-1 - a potential therapeutic target in cancer Curr Drug Targets 8(9): 1030-1041.

40. Cortese K, Cortese K, Sahores M, Madsen CD, Tacchetti C, et al. (2008) Clathrin and LRP-1-independent constitutive endocytosis and recycling of uPAR. PLoS One 3(11): e3730.

41. Harley W, Floyd C, Dunn T, Zhang XD, Chen TY, et al. (2010) Dual inhibition of sodium-mediated proton and calcium efflux triggers nonapoptotic cell death in malignant gliomas. Brain Res 1363:159-169.

42. Rowson Hodel AR, Berg AL, Wald JH, Hatakeyama J, VanderVorst K, et al. (2016) Hexamethylene amiloride engages a novel reactive oxygen species- and lysosome-dependent programmed necrotic mechanism to selectively target breast cancer cells. Cancer Lett 375(1): 62-72.

43. Zhang X, Bu X, Zhen H, Fei Z, Wu J, et al. (2000) Expression and significance of urokinase-type plasminogen activator in human gliomas. Chin Med J (Engl) 113(9): 802-804.

44. Olmez, Wangzhen Shen, Hayes McDonald, Bulent Ozpolat (2015) Dedifferentiation of patient-derived glioblastoma multiforme cell lines results in a cancer stem cell-like state with mitogen-independent growth. Journal of Cellular Molecular Medicine 19(6): 1262-1272.

45. Auffinger B, Tobias AL, Han Y, Lee G, Guo D et al. (2014) Conversion of differentiated cancer cells into cancer stem-like cells in a glioblastoma model after primary chemotherapy. Cell Death Differ 21(7): 11191131.

46. Schnier JB, Nishi K, Harley WR, Gorin FA (2008) An acidic environment changes cyclin D1 localization and alters colony forming ability in gliomas. J Neurooncol 89(1): 19-26.

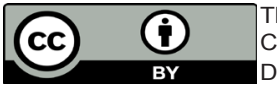

his work is licensed under Creative Commons Attribution 4.0 Licens

DOI: 10.19080/OAJNN.2018.07.555712
47.http://appft1.uspto.gov/netacgi/nph-Parser?Sect1=PT01\& Sect $2=$ HITOFF $\& d=P G 01 \& p=1 \& u=/$ netahtml $/$ PTO $/$ srchnum. html\&r=1\&f=G\&l=50\&s1=20120108494

48. Nykjaer A, Kjøller L, Cohen RL, Lawrence DA, Garni-Wagner BA, et al. (1994) Regions involved in binding of urokinase-type-1 inhibitor complex and pro-urokinase to the endocytic alpha 2-macroglobulin receptor/low density lipoprotein receptor-related protein. Evidence that the urokinase receptor protects pro-urokinase against binding to the endocytic receptor. J Biol Chem 269(41): 25668-25676.

49. Duffy MJ (2004) The urokinase plasminogen activator system: role in malignancy. Curr Pharm Des 10(1): 39-49.

50. Iwadate Y, Hayama M, Adachi A, Matsutani T, Nagai Y, et al. (2008) High serum level of plasminogen activator inhibitor-1 predicts histological grade of intracerebral gliomas. Anticancer Res 28(1B): 415-418.

51. Czekay RP, Loskutoff DJ (2004) Unexpected role of plasminogen activator inhibitor 1 in cell adhesion and detachment. Exp Biol Med (Maywood) 229(11): 1090-1096.

52. Garner JM, Ellison DW, Finkelstein D, Ganguly D, Du Z et al. (2015) Molecular heterogeneity in a patient-derived glioblastoma xenoline is regulated by different cancer stem cell populations. PLoS One 10(5): e0125838.

53. Li Y, Knisely JM, Lu W, Mc Cormick LM, Wang J, et al. (2002) Low density lipoprotein (LDL) receptor-related protein 1B impairs urokinase receptor regeneration on the cell surface and inhibits cell migration. J Biol Chem 277(44): 42366-42371.

54. Maitland NJ, Collins AT (2010) Cancer stem cells - A therapeutic target? Curr Opin Mol Ther 12(6): 662-673.

\section{Your next submission with Juniper Publishers} will reach you the below assets

- Quality Editorial service

- Swift Peer Review

- Reprints availability

- E-prints Service

- Manuscript Podcast for convenient understanding

- Global attainment for your research

- Manuscript accessibility in different formats

( Pdf, E-pub, Full Text, Audio)

- Unceasing customer service

Track the below URL for one-step submission https://juniperpublishers.com/online-submission.php 